University of Nebraska - Lincoln

DigitalCommons@University of Nebraska - Lincoln

$1-28-2000$

\title{
Correcting eddy-covariance flux underestimates over a grassland
}

T. E. Twine

University of Wisconsin-Madison

W. P. Kustas

USDA-ARS Hydrology Laboratory, Beltsville, MD

J. M. Norman

University of Wisconsin - Madison

D. R. Cook

Argonne National Laboratory, Argonne, IL

P. R. Houser

NASA Goddard Space Flight Center, Greenbelt, MD

See next page for additional authors

Follow this and additional works at: https://digitalcommons.unl.edu/nasapub

Part of the Physical Sciences and Mathematics Commons

Twine, T. E.; Kustas, W. P.; Norman, J. M.; Cook, D. R.; Houser, P. R.; Meyers, T. P.; Prueger, J. H.; Starks, P. J.; and Wesley, M. L., "Correcting eddy-covariance flux underestimates over a grassland" (2000). NASA Publications. 11.

https://digitalcommons.unl.edu/nasapub/11

This Article is brought to you for free and open access by the National Aeronautics and Space Administration at DigitalCommons@University of Nebraska - Lincoln. It has been accepted for inclusion in NASA Publications by an authorized administrator of DigitalCommons@University of Nebraska - Lincoln. 


\section{Authors}

T. E. Twine, W. P. Kustas, J. M. Norman, D. R. Cook, P. R. Houser, T. P. Meyers, J. H. Prueger, P. J. Starks, and M. L. Wesley 


\title{
Correcting eddy-covariance flux underestimates over a grassland
}

\author{
T.E. Twine ${ }^{a, *}$, W.P. Kustas ${ }^{\text {b }}$, J.M. Norman ${ }^{c}$, D.R. Cook ${ }^{d}$, P.R. Houser ${ }^{\text {e }}$, T.P. Meyers ${ }^{f}$, \\ J.H. Prueger ${ }^{\mathrm{g}}$, P.J. Starks ${ }^{\mathrm{h}}$, M.L. Wesely ${ }^{\mathrm{d}}$ \\ ${ }^{a}$ Department of Atmospheric and Oceanic Sciences, 1225 West Dayton St., University of Wisconsin-Madison, Madison, WI 53706, USA \\ ${ }^{\mathrm{b}}$ USDA-ARS Hydrology Laboratory, Beltsville, MD 20705, USA \\ ${ }^{c}$ Department of Soil Science, University of Wisconsin-Madison, Madison, WI 53706, USA \\ d Argonne National Laboratory, Argonne, IL 60439, USA \\ ${ }^{e}$ Hydrological Sciences Branch, NASA Goddard Space Flight Center, Greenbelt, MD 20771, USA \\ ${ }^{\mathrm{f}}$ NOAA Atmospheric Turbulence and Diffusion, Oak Ridge National Laboratory, Oakridge, TN 37831, USA \\ ${ }^{g}$ USDA-ARS National Soil Tilth Laboratory, Ames, IA 50011, USA \\ ${ }^{\text {h }}$ USDA-ARS Grazinglands Research Laboratory, El Reno, OK 73036, USA
}

Received 9 April 1999; received in revised form 28 January 2000; accepted 28 January 2000

\begin{abstract}
Independent measurements of the major energy balance flux components are not often consistent with the principle of conservation of energy. This is referred to as a lack of closure of the surface energy balance. Most results in the literature have shown the sum of sensible and latent heat fluxes measured by eddy covariance to be less than the difference between net radiation and soil heat fluxes. This under-measurement of sensible and latent heat fluxes by eddy-covariance instruments has occurred in numerous field experiments and among many different manufacturers of instruments. Four eddy-covariance systems consisting of the same models of instruments were set up side-by-side during the Southern Great Plains 1997 Hydrology Experiment and all systems under-measured fluxes by similar amounts. One of these eddy-covariance systems was collocated with three other types of eddy-covariance systems at different sites; all of these systems under-measured the sensible and latent-heat fluxes. The net radiometers and soil heat flux plates used in conjunction with the eddy-covariance systems were calibrated independently and measurements of net radiation and soil heat flux showed little scatter for various sites. The $10 \%$ absolute uncertainty in available energy measurements was considerably smaller than the systematic closure problem in the surface energy budget, which varied from 10 to $30 \%$. When available-energy measurement errors are known and modest, eddy-covariance measurements of sensible and latent heat fluxes should be adjusted for closure. Although the preferred method of energy balance closure is to maintain the Bowen-ratio, the method for obtaining closure appears to be less important than assuring that eddy-covariance measurements are consistent with conservation of energy. Based on numerous measurements over a sorghum canopy, carbon dioxide fluxes, which are measured by eddy covariance, are underestimated by the same factor as eddy covariance evaporation measurements when energy balance closure is not achieved. Published by Elsevier Science B.V.
\end{abstract}

Keywords: Eddy-covariance; Friction velocity; Evapotranspiration flux

\section{Introduction}

* Corresponding author. Fax: +1-608-263-4190.

E-mail address: tetwine@students.wisc.edu (T.E. Twine)
A better understanding of how energy and mass are partitioned at the earth's surface is necessary for

0168-1923/00/\$ - see front matter Published by Elsevier Science B.V.

PII: S0168-1923(00)00123-4

This article is a U.S. government work, and is not subject to copyright in the United States. 
improving regional weather and global climate models. Because measurements of scalar fluxes can only be made at a few locations, these weather and global climate models will be used to assess the impact of societal choices, such as abiding by the Kyoto Protocol for carbon sequestration. Usually surface flux models are only as accurate as the measurements used to validate them; therefore, accurate measurements of surface energy components are imperative for accurate modeling of surface energy and mass balances. The importance of accurate micrometeorological measurements of surface fluxes is a justification for long-term flux measurement networks (Baldocchi et al., 1996). Unfortunately, the micrometeorological literature contains numerous anecdotal references to possible systematic underestimates of surface scalar fluxes by the preferred measurement system; namely eddy covariance (Dugas et al., 1991; Nie et al., 1992; Fritschen et al., 1992; Goulden et al., 1997; McCaughey et al., 1997; Mahrt, 1998). The potential problems that systematic errors can create in long-term surface flux measurements, particularly selective systematic errors (different daytime errors from night-time errors), are considered by Moncrief et al. (1996) and can be serious. Therefore, dealing with lack of energy-balance closure should be considered in the standards for long-term, flux-measurement networks even though it has received little attention (Baldocchi et al., 1996).

All models of surface energy and mass exchange are based on the fundamental conservation principles; namely, conservation of energy and conservation of mass. The major components of the conservation of energy equation, which we often refer to as 'energy-balance closure', can be depicted as

$\mathrm{Rn}=H+\mathrm{LE}+G+S+\varepsilon$,

where $\mathrm{Rn}$ is net radiation, $H$ is convective sensible heat exchange, LE is latent heat exchange or evapotranspiration, $G$ is the soil-surface heat conduction flux, $S$ is the heat storage in the canopy and $\varepsilon$ is any residual flux associated with errors. This equation neglects energy partitioned to photosynthesis, which is less than a few percent of the net radiation. If field measurements of surface fluxes are not consistent with Eq. (1), then modelers will have to make adjustments to the mea- sured fluxes or accept uncertainties in their models that are of the same magnitude as the measured energy conservation discrepancy. Because the discrepancy in energy-balance closure $(D=[H+\mathrm{LE}] /[\mathrm{Rn}-G-S])$ is a bias that varies from 0 to $-30 \%(0.7<D<1)$, this problem is serious if the cause for this discrepancy is not known. With $D<0.7$, the utility of the sensible and latent heat flux measurements for model validation or calibration is greatly reduced (Kustas et al., 1999). Operationally, a systematic error that underestimates the evapotranspiration component of a water budget of a crop by $25 \%$ is intolerable to an irrigation scheduler. By half-way through a growing season, the underestimated portion of the evaporation could accumulate to an amount of water equivalent to half the total soil moisture available to the crop and result in erroneous predictions of severe yield reductions if not corrected. Likewise, the underestimation of a daytime net $\mathrm{CO}_{2}$ flux by $25 \%$ could easily lead one to conclude that a forest site was a net source of carbon when in fact it was a significant sink of carbon; because night-time fluxes are estimated by alternative methods that may not underestimate respiratory fluxes (Moncrief et al., 1996).

The micrometeorological measurement community should resolve these serious discrepancies in the energy-balance closure to provide guidance to the modeling community on how to interpret flux measurements that do not appear to be consistent with the conservation principles (Kustas et al., 1999). The objective of this paper is to suggest a method for treating micrometeorological measurements of surface fluxes that do not appear to be consistent with conservation of energy. Extensive measurements from the Southern Great Plains 1997 Hydrology Experiment in Oklahoma in 1997 (SGP97) are used to investigate closure of the energy balance. The accuracy of $\mathrm{Rn}$ and $G$ will be evaluated and a procedure proposed for closing the energy budget. The measurement strategy employed here was to make extensive measurements simultaneously at one ideal collocation site (ER01) using as many instruments as possible with independent calibrations on all the individual sensors. Then one of the instruments from this collocation site was mounted next to instrumentation at other permanent sites to obtain paired comparisons at different sites with sensors from various manufacturers and research groups. 


\section{Review of surface flux measurements and energy-balance closure}

Two primary micrometeorological systems for measuring surface scalar fluxes are in wide-spread use; the energy-balance-Bowen-ratio (EBBR) method and the eddy-covariance (EC) method (Dabberdt et al., 1993). The EBBR method uses direct measurements of Rn, $G$, and gradients of temperature and water vapor in the atmosphere to estimate LE and $H$ by assuming similarity between heat and water vapor transport and conservation of energy. The EC method is based on direct measurements of the product of vertical velocity fluctuations $\left(w^{\prime}\right)$ and scalar concentration fluctuations $\left(c^{\prime}\right)$ yielding a direct estimate of $H$ and LE assuming the mean vertical velocity is negligible. Clearly the EBBR method must be consistent with conservation of energy because it forces energy-balance closure; however, the EC method provides estimates of $H$ and LE separately so that when combined with measurements of Rn, $G$, and $S$ all the major components of the energy balance are independently measured.

Several reasons for lack of closure of the surface energy budget have been discussed by Mahrt (1998) and may include the following: (1) lack of coincidence of the source areas among various flux components measured very near a surface such as evaporation coming from leaves and sensible heat from a hot, dry soil surface; (2) flux divergence arising from transport that is not one-dimensional such as insufficient fetch; (3) non-stationarity of measured time series over the typical $30 \mathrm{~min}$ averaging periods so that covariance arising from very low frequency fluctuations is missed; (4) turbulent dispersive fluxes arising from organized planetary-boundary-layer circulations that may have preferred locations so that the mean vertical velocities at an instrument location may be systematically different from zero giving rise to a vertical advective flux; and (5) measurement errors related to sensor separation, frequency response, alignment problems, and interference from tower or instrument-mounting structures.

The accuracy of the measurement of surface energy fluxes can be assessed two ways to increase confidence in the evaluation: (1) Evaluate the closure of the surface energy balance using independent measurements of all the components of the energy budget contained in Eq. (1) and (2) compare measure- ments at the same time and same site using EC and EBBR instrumentation. Closure can be quantified using $D=[H+\mathrm{LE}] /[\mathrm{Rn}-G-S]$ or specified as a residual flux density, $\varepsilon$.

Agreement between two independent methods for measuring surface fluxes increases confidence in both approaches; therefore, comparisons between the EC and EBBR methods are valuable. The EBBR method, which is based on measurements of temperature and vapor pressure gradients, provides estimates of $H$ and LE that are independent of the EC method even though Rn, $G$ and $S$ would not be independent. Because the EBBR method assumes closure of the energy budget to solve for $H$ and $\mathrm{LE}$, differences between EBBR and EC methods include the lack of closure issue with the EC method along with differences of measured Bowen-ratios.

Closure was assessed over grassland ecosystems during the FIFE experiment (Sellers et al., 1992), and in a semi-arid environment during Monsoon'90 (Stannard et al., 1994). During the FIFE experiment, Nie et al. (1992) found that the four flux components measured by an EC system summed to a maximum residual of $160 \mathrm{~W} \mathrm{~m}^{-2}$. An EC system and EBBR system were collocated at site 926 for 3 days. The closure rate for the eddy-covariance system averaged 0.84 over the period of comparison (Fritschen et al., 1992). Sensible heat fluxes between both systems compared better than latent heat fluxes. Investigators noted that the systems were located $30 \mathrm{~m}$ apart at a heavily grazed site, which may have made fluxes found from either system unrepresentative of the entire area.

During the dry season of Amazonia, Wright et al. (1992) measured a closure rate of $99 \%$ when available energy was above $30 \mathrm{~W} \mathrm{~m}^{-2}$ over a ranchland of prairie grasses with patches of bare soil. Bowen-ratio $(\beta)$ values increased from 0.43 to 0.67 as the dry season progressed. In contrast to this excellent closure rate from Amazonia, where Bowen-ratios were relatively small, some experiments have shown that fluxes may approach closure under dry conditions with large Bowen-ratios. At a semi-arid Sonoran desert site, Unland et al. (1996) measured fluxes to within an average closure of $96 \%$ over a year. Unfortunately, no data were available to show if, or how, closure rates changed after precipitation during either of these studies, but during the dry season in Arizona, flux measurements from Stannard 
et al. (1994) showed little change in closure after a rainfall.

The largest residual to energy budget closure during the Monsoon'90 experiment (Kustas et al., 1991) occurred at the poorest-rated site (in terms of flatness and slope), with a value of $36 \mathrm{~W} \mathrm{~m}^{-2}$ (Stannard et al., 1994). Typical midday Bowen-ratio values were near 1.0. The $H$ and LE fluxes were believed to be under-measured because this was a sloping site and mean vertical wind speed may not have been equal to zero. Even coordinate rotation corrections do not compensate completely for severe slope conditions. The smallest residual was $2 \mathrm{~W} \mathrm{~m}^{-2}$, which occurred at the best-rated site. Stannard et al. (1994) were able to eliminate flux divergence, mismatch of source areas, and over-measurement of available energy as reasons for non-closure. They concluded that under-measurement of $H$ and LE was most likely.

During the BOREAS experiment (Sellers et al., 1997), $24 \mathrm{~h}$ average closure rates over the boreal forest ranged from $68 \%$ over dry jack pine (McCaughey et al., 1997), to $97 \%$ over black spruce (Jarvis et al., 1997). Energy-balance closure over a forest includes heat storage in stems, leaves, and air column, and energy used in photosynthesis. Measurements from a different black spruce forest within the BOREAS region resulted in closure rates as low as $80 \%$ without accounting for storage or soil heat flux (Goulden et al., 1997). Typically soil and canopy storage fluxes are less than $5 \%$ of net radiation in mature black spruce forests (Jarvis et al., 1997). Goulden et al. (1997) found no errors in instrument calibration and no non-linearity between friction velocity and vertical wind speed during neutral stability periods. They also found that lack of closure was independent of the Bowen-ratio, which led them to conclude that neither the $H$-measuring instrument nor the LE-measuring instrument were biased. Fluxes approached closure under three conditions: in the middle to late afternoon, when the wind came from a certain direction, and when friction velocity was relatively large. The variation of closure rate with wind direction may have proven that some areas within the measuring region were not homogeneous. The change in closure rate with friction velocity may have proven that the flow was not stationary during some sampling periods. Goulden et al. (1997) also concluded that the change in closure rate with time of day proved that a change in storage did not contribute to lack of closure.

The boreal forest has been suggested to contain the missing 'sink' of the global carbon budget. If, in fact, more transpiration is occurring than what has been measured with EC systems, this probably means that more photosynthesis is also occurring; therefore, the storage of carbon in biomass may also be more than what has been estimated (Goulden et al., 1998).

During an experiment in Amazonia, Wright et al. (1992) found excellent agreement between flux measurements from the EC method and the EBBR method. Over a 4-day measurement period, the average deviation of measurements from both methods from the hourly average of evaporation was $21 \mathrm{~W} \mathrm{~m}^{-2}$. Dugas et al. (1991) set three EC systems next to four EBBR systems in an irrigated wheat field in Arizona for a 2-day experiment. Bowen-ratios and sensible heat fluxes were negative the entire time due to advection from an adjacent dry bare-soil field. EC closure averaged near $70 \%$ over both the days of the experiment. They found that the EC measurements came closest to closure at times when latent heat fluxes were similar to those estimated by the EBBR systems. From the 2 days of data discussed, these times were between noon and sundown for 1 day, where the Bowen-ratio decreased from -0.2 to -1 , and only near sundown on the other day, where the Bowen-ratio decreased from -0.4 to -0.8 . At all other times the EC latent heat flux was lower than the EBBR latent heat flux. EC sensible heat fluxes were also less than EBBR estimates, but the magnitude of this bias was less than the variation in $\mathrm{H}$ values from four EBBR systems.

From an irrigated wheat field experiment in Arizona, the small differences in sensible heat flux and large underestimates of latent heat flux from the EC systems, as compared with the EBBR systems, led Dugas et al. (1991) to believe that lack of closure was due to an underestimation of latent heat flux. Ashktorab et al. (1989) found good agreement between lysimeter measurements of latent heat flux, latent heat flux estimated from a micro-Bowen-ratio system, and latent heat flux calculated as a residual to the energy budget using eddy-covariance sensible heat fluxes over bare soil during moist and second-stage drying conditions. Over a grass-covered clearcut in British Columbia, Adams et al. (1991) calculated latent heat flux as a residual using EC measurements of sensible 
heat flux. EBBR latent heat fluxes were $30 \%$ smaller than those determined by residual-LE closure, due in part to larger estimates of $H$ with the EBBR system.

The relative uncertainties associated with measurements of soil heat conduction flux can be large because the area of measurement is several orders of magnitude smaller than the averaging area of eddy-covariance measurements. The unequal thermal conductivities of the heat flux plate and surrounding soil can cause divergence/convergence errors; usually these errors are small because heat flux plates are made with conductivities that are midway in the conductivity range of soils. VanLoon et al. (1998) describe a method for calibration that accounts for the difference in thermal conductivity between the plate and soil. To avoid problems with blocking liquid and water vapor movement, heat flux plates are buried at a depth of $5-10 \mathrm{~cm}$ and temperature and water content measurements in the layer above the plate are used to estimate heat storage above the heat flux plate. Adjusting for the heat storage above the plate can be a major source of error. Fortunately the soil conduction flux for fully vegetated surfaces is relatively small, typically $5-10 \%$ of the net radiation during midday. Stannard et al. (1994) found good agreement over a 14-day period among soil surface heat flux measurements from three REBS HFT-3 plates; the kind of plates used in the SGP97 experiment.

\section{Methods for energy-balance closure}

The use of surface flux data to validate land surface models requires that conservation of energy be satisfied; therefore, the measured energy budget must be closed by some method. As we will discuss later, the net radiation is probably the most accurate measurement (accurate to about 5-7\%) of the major components of the surface energy balance for large homogeneous sites even though some studies have reported otherwise based on past measurements with particular instruments (Field et al., 1992; Halldin and Lindroth, 1992). Halldin and Lindroth (1992) compared instruments from six different manufacturers and noted that differences with a four-component system ranged from 6 to $20 \%$. Moreover, they found that on-site calibration of the instruments varied by as much as $30 \%$ from the manufacturers' calibration. Al- though poorly designed or calibrated instruments may have large errors, with reasonable care and knowledge errors of $6 \%$ in $\mathrm{Rn}$ are achievable. Of this $6 \%$ error in $\mathrm{Rn}$, typically $3 \%$ may arise from an uncertainty of $3 \%$ in the net solar radiation and the remaining $3 \%$ comes from a $15 \%$ uncertainty in the net thermal radiation. For canopies of full cover, such as those studied in this comparison, the maximum value of $G$ is less than about $100 \mathrm{~W} \mathrm{~m}^{-2}$, while the typical uncertainty in the mean of measurements from two locations is less than about $15 \mathrm{~W} \mathrm{~m}^{-2}$; most of this uncertainty arises from spatial sampling. The resultant, total, probable error of $\mathrm{Rn}-G$, including the random uncertainty in $G$, is $10 \%$ for homogeneous sites. At least $1 / 3$ of this $10 \%$ error, that arising from soil heat flux, should be random because of spatial sampling and water content uncertainties, so that only a 6-7\% bias in energy-balance closure should be apparent in the available energy. Based on this discussion, and more details that follow, the shortfall in energy-balance closure is most reasonably removed by adjusting $H$ and LE.

Closure is most reasonably forced by assuming that the measured available energy $(\mathrm{Rn}-G)$ is representative of the area measured by the EC system so that $H$ and LE are adjusted. On the other hand for heterogeneous sites, such as those containing clumped vegetation with large patches of bare soil, forcing closure may be tenuous because obtaining representative $\mathrm{Rn}-G$ observations is very difficult (Lloyd et al., 1997). One option of forcing closure is to assume that $H$ is accurately measured, and solve for LE as a residual to the energy-balance equation. We refer to this method as the 'residual-LE closure'. This approach is implicitly used when investigators measure Rn, $G$, and $H$ and estimate LE as a residual (Adams et al., 1991; Ashktorab et al., 1989; Fitzjarrald and Moore, 1994; Stannard et al., 1994). This method of closure is appealing because the measurements of LE are ignored. Another option is to assume that $\beta$ is correctly measured by the EC system so that individual values of $H$ and LE can be adjusted to balance Eq. (1) (Barr et al., 1994; Blanken et al., 1997). We refer to this method as 'Bowen-ratio closure'. Although investigators have used both the closure methods, no compelling evidence exists to discard measurements of LE because comparisons of various sensors show agreement (Sauer et al., 1995; Katul et al., 1999). Furthermore, similarity of sensible and latent heat 
fluxes at heights greater than the roughness sublayer is expected. For these two reasons, we suggest that Bowen-ratio closure may be the most appropriate.

\section{Field measurement methods}

The Southern Great Plains 1997 Hydrology Experiment (SGP97), sponsored by NASA and USDA, took place in Oklahoma during June and July of 1997 (Jackson, 1997). The main objectives of SGP97 were to study the remote sensing of soil moisture and the effect of soil moisture on the development of the atmospheric boundary layer and clouds over the SGP97 region during the warm season (Jackson, 1997). One aspect of the project was the measurement of surface fluxes at numerous locations across the SGP97 region.

Surface flux measurements were compared from seven of the 11 sites within the SGP97 region where surface flux measurements were made. This region included three main study areas: (1) The Department of Energy's Atmospheric Radiation Measurement (ARM) experiment at the Southern Great Plains Cloud And Radiation Testbed (CART) Central Facility, (2) the USDA Agricultural Research Service (ARS) Grazinglands Research Lab in El Reno, OK and (3) the Little Washita watershed. The total area extended from about $34.5-37^{\circ}$ North latitude and from 97 to $99^{\circ}$ West longitude. Land cover varied from bare fields to fully vegetated rangeland. Fluxes were measured or estimated from eddy-covariance (EC) systems and energy-balance-Bowen-ratio (EBBR) systems from several manufacturers. Table 1 lists SGP97 surface flux site identifiers and locations along with a description of the sites and approximate canopy heights.
All SGP97 EC systems obtained 30 min-average values of $\mathrm{Rn}, H$, LE, and $G$. In addition, mean and standard deviations were obtained for air temperature, windspeed, wind direction, friction velocity, and vapor pressure. EBBR systems measured net radiation, Bowen-ratio, and soil-surface heat flux. All systems that measured soil heat flux used the average output of at least two heat flux plates buried at nominal depths of $0.07 \mathrm{~m}$ with thermocouples at two depths to account for heat storage between the plate and the soil surface. The ARM-operated EBBR systems also measured soil moisture between the plates and the soil surface. Soil moisture in the top $5 \mathrm{~cm}$ was also measured at the other sites except for LW02. When multiple measurement locations for $G$ were available at a site, a site-averaged value of soil-surface heat flux was then determined in the hope of obtaining the best spatially representative value. System identifiers, descriptions and instruments are listed in Table 2.

Some surface flux measurement systems were collocated at site ER01 at the Grazinglands Lab for a week before the experiment began for intercomparison and shakedown efforts. A recent rain event produced a homogeneous surface over most sites at the Grazinglands Lab. At this time, the UW-CNR1, Kipp and Zonen, four-way, net radiometer was collocated with five net radiometers over the USDA-ARS Grazinglands Research Lab parade ground.

As part of the comparison strategy, one of the instruments from the collocation comparison site was mounted next to instrumentation at other permanent sites to obtain paired comparisons at different locations with sensors from various manufacturers and research groups. The University of Wisconsin-Madison used a Campbell Scientific Instruments, (CSI) CSAT3,

Table 1

Site identifier, site location, site description, and canopy height for SGP97 data used in this study

\begin{tabular}{llll}
\hline Site ID & Latitude/Longitude & Description & Canopy height (m) \\
\hline CF02 & $36^{\circ} 36^{\prime} 15.3^{\prime \prime} \mathrm{N} 97^{\circ} 29^{\prime} 12.84^{\prime \prime} \mathrm{W}$ & Harvested winter wheat; remaining stubble \\
ER01 & $35^{\circ} 33^{\prime} 25.2^{\prime \prime} \mathrm{N} 98^{\circ} 00^{\prime} 58.78^{\prime \prime} \mathrm{W}$ & Densely vegetated rangeland & 0 \\
ER05 & $35^{\circ} 32^{\prime} 54.4^{\prime \prime} \mathrm{N} 98^{\circ} 02^{\prime} 11.57^{\prime \prime} \mathrm{W}$ & Densely vegetated rangeland & $0.5-1.0$ \\
ER09 & $35^{\circ} 33^{\prime} 54.79^{\prime \prime} \mathrm{N} 98^{\circ} 03^{\prime} 47.48^{\prime \prime} \mathrm{W}$ & Heavily grazed pasture & $0.5-1.0$ \\
ER13 & $35^{\circ} 32^{\prime} 27.85^{\prime \prime} \mathrm{N} 98^{\circ} 03^{\prime} 43.48^{\prime \prime} \mathrm{W}$ & Plowed soil; some wheat stubble & 0.25 \\
LW02 & $35^{\circ} 00^{\prime} 51.55^{\prime \prime} \mathrm{N} 98^{\circ} 00^{\prime} 20.06^{\prime \prime} \mathrm{W}$ & Heavily grazed pasture & $0.1-0.3$ \\
LW03 & $34^{\circ} 57^{\prime} 25.2^{\prime \prime} \mathrm{N} 98^{\circ} 04^{\prime} 33.6^{\prime \prime} \mathrm{W}$ & Heavily grazed pasture & $0.25-0.5$ \\
LW08 & $34^{\circ} 52^{\prime} 58.8^{\prime \prime} \mathrm{N} 98^{\circ} 12^{\prime} 18.0^{\prime \prime} \mathrm{W}$ & Winter wheat & 0.6 \\
\hline
\end{tabular}


Table 2

System identifier, system description, flux instruments, and EC processing methods for systems involved in this study

\begin{tabular}{|c|c|c|}
\hline System & Description & Flux instruments \\
\hline CF02ARM & $\begin{array}{l}\text { ARM EC system (permanent) } \\
\text { E14 ARM identifier }\end{array}$ & $\begin{array}{l}\text { Applied technologies 3-D sonic anemometer Model } \\
\text { SWS-211/3Sx, Analytic Applications infrared hygrometer } \\
\text { Model M100 } \\
\text { Three-minute average flux high-pass filter, 3-D coordinate } \\
\text { rotation }\end{array}$ \\
\hline $\mathrm{CF} 02 \mathrm{PH}$ & $\begin{array}{l}\text { University of Arizona } \\
\text { EC system }\end{array}$ & $\begin{array}{l}\text { Solent 3-D sonic anemometer 1012R2A, Li-Cor LI- } 6262 \\
\text { Infrared Gas Analyzer, REBS HFT3-L soil heat flux plates, } \\
\text { Campbell Scientific. 2X2 (TCAV-L) averaging thermocouple } \\
\text { Three-minute average flux high-pass filter, online corre- } \\
\text { ctions for coordinate rotation, sensor frequency response, } \\
\text { path length averaging, sensor separation, and for damping } \\
\text { of fluctuations during flow down the ducting tube }\end{array}$ \\
\hline ER01ARM & $\begin{array}{l}\text { ARM EBBR system (permanent) } \\
\text { E19 ARM identifier }\end{array}$ & REBS-SEBS $^{\mathrm{a}}$ \\
\hline $\begin{array}{l}\text { ER01JPBK } \\
\text { ER05JPBK } \\
\text { ER09JPBK } \\
\text { ER13JPBK }\end{array}$ & USDA-ARS EC systems & $\begin{array}{l}\text { Campbell Scientific. CSAT3 sonic anemometer, KH20 } \\
\text { Krypton hygrometer, REBS HFT3-L soil heat flux plates, } \\
\text { Campbell Scientific 2X2 (TCAV-L) averaging } \\
\text { thermocouple; }\end{array}$ \\
\hline ER01JPBK2 & $\begin{array}{l}\text { Second USDA-ARS EC system at } \\
\text { ER01 moved and became ER05JPBK }\end{array}$ & $\begin{array}{l}\text { Ten-minute average flux high-pass filter, no coordinate } \\
\text { rotation }\end{array}$ \\
\hline ER01PS & $\begin{array}{l}\text { USDA-ARS } \\
\text { EBBR system }\end{array}$ & Campbell Scientific. Bowen-ratio system ${ }^{b}$ \\
\hline LW02TM & GEWEX EC system (permanent) & $\begin{array}{l}\text { Solent 3-D sonic anemometer Model R2, NOAA/ } \\
\text { ARL/ATDD open-path infrared gas analyzer, REBS } \\
\text { HFT-3 soil heat flux plates, NOAA/ARL/ATDD } \\
\text { thermocouples; } \\
\text { Seven-minute average flux high-pass filter, 2-D coordinate } \\
\text { rotation }\end{array}$ \\
\hline LW03ARM & $\begin{array}{l}\text { ARM EBBR system (permanent) } \\
\text { E26 ARM identifier }\end{array}$ & REBS-SEBS $^{\mathrm{a}}$ \\
\hline
\end{tabular}

${ }^{a}$ Radiation energy balance systems surface energy balance system: Chromel-constantan thermocouple, Omega Engineering, REBS Model \# ATP-1, Capacitive element, Vaisala, Model \#s HMP 35A and HMP35D, Platinum Resistance Temperature Detector, MINCO Products, REBS Model \#STP-1, MINCO Model \#XS11PA40T260X36(D) with soil heat flow probes, radiation \& energy balance systems, Model \#s HFT-3, HFT3.1.

${ }^{\mathrm{b}}$ Campbell Bowen-ratio System: Li-Cor LI-6262 CO2/H2O analyzer, Type E fine-wire thermocouples (TCBR-3), REBS HFT-3 soil heat flux transducers, Campbell Scientific 2X2 (TCAV) averaging thermocouple.

3-D Sonic Anemometer (Campbell Scientific Instruments, Logan, UT) to measure the three wind components and sensible heat flux, a Campbell Scientific Instruments Inc. KH20 Krypton hygrometer to measure latent heat flux, and a Kipp and Zonen CNR1 four-way net radiometer (Kipp and Zonen, Delft, Holland) to measure net radiation. This system will hereafter be referred to as the UW EC system. The UW EC system measured the same fluxes as other EC systems and used three $10 \mathrm{~min}$ average flux values to determine one $30 \mathrm{~min}$ average. No corrections were performed on data to account for sensor separation because calculations indicated adjustments to the fluxes of less than 3\% (Moore, 1986). Coordinate rotations were not performed on UW data; such rotations rarely alter scalar fluxes by more than $5 \%$ or $30 \mathrm{~W} \mathrm{~m}^{-2}$ for homogeneous, flat sites (Bertrand Tanner, Campbell Scientific, pers. commun.). In fact, frequently coordinate rotations can lead to spurious flux results when wind speeds are light or large changes in wind 
Table 3

Summary of site location, number of days at site, and instrument heights for the UW roving eddy-covariance system measurement of sensible and latent heat fluxes

\begin{tabular}{lll}
\hline Site UW system & Days & Height (meters above soil surface) \\
\hline ER01 & 4 & 2.0 \\
LW02 & 3 & 3.5 \\
LW03 & 3 & 2.6 \\
ER13 & 7 & 3.0, JPBK was at 2.0 \\
CF02 & 4 & 3.0 \\
\hline
\end{tabular}

direction occur during an averaging period. Coordinate rotations were performed on sensors at CF02ARM, CF02PH and LW02TM.

After the comparison of eddy-covariance systems at site ER01, the various systems were taken to their designated locations for the remainder of the experiment. One system, the University of Arizona EC system was stationed at ER01 for half of the experiment and was then moved to $\mathrm{CF} 02$ for the remainder of the experiment. Only the UW EC system was moved about from site to site during the experiment to compare flux measurements and to calibrate net radiometers to the UW reference. This strategy provides for a comparison of several eddy-covariance systems at the same site; then a second comparison at another site. Sites visited, duration of stay, and heights of instruments for the UW EC system are shown in Table 3. UW instruments were placed at the same height as the other instruments except at ER13 where the UW instruments were placed one meter above the JPBK instruments.

The soil-surface heat flux is estimated from a combination of REBS (Radiation Energy Balance Systems, Seattle, WA) heat flux plates and the heat storage in the soil layer above the plates. Four REBS HFT-3 plates used in SGP97 were calibrated with a specially designed system at the University of Wisconsin-Madison laboratories. The plates were placed in the middle of an insulated box measuring $0.66 \mathrm{~m}$ by $0.71 \mathrm{~m}$ by $0.2 \mathrm{~m}$ that was filled with quartz sand. The conductivity of the dry quartz sand $\left(0.77 \mathrm{~W} \mathrm{~m}^{-1} \mathrm{~K}^{-1}\right)$ was midway between the likely soil conductivity variation in the field of $0.5-1.3 \mathrm{~W} \mathrm{~m}^{-1} \mathrm{~K}^{-1}$, and the absence of water minimized errors from latent heat associated with water movement. Heat storage in the soil layer above the plates, which was based on two temperature measurements, gravimetric soil water content and bulk density measurements, usually accounted for about half of the total surface heat flux.

\section{Results}

If the measurements of the components of the surface energy budget given by Eq. (1) do not balance, the discrepancy may arise from errors in any flux component. Identifying the flux components most likely to be responsible for the lack of energy-balance closure requires establishing the absolute accuracy of as many flux components as possible. Therefore, the results address the absolute accuracy of radiation and heat storage measurements and then consider comparisons among eddy-covariance measurements.

\subsection{Accuracy of available energy measurements}

\subsubsection{Net radiation}

Net all-wave radiation is composed of net solar radiation and net thermal radiation. Solar radiation measurements are probably the most accurate measurements of all the components in the surface energy budget, and they represent the largest part of the net radiation. We divide the uncertainty surrounding net solar radiation measurements into two issues: (1) Absolute accuracy of the measurements and (2) spatial sampling associated with the reflected solar radiation. A major focus of the Atmospheric Radiation Measurement (ARM) experiment is the accurate measurement of solar radiation. By using cavity radiometers as references, ARM solar radiation measurements with pyranometers are accurate to $2.5 \%$ (BORCAL, 1997). This accuracy is achieved by comparisons with standards from the National Renewable Energy Laboratory (NREL), Golden, CO; and NREL traces their references to the World Radiometric Reference by participating in the International Pyrheliometer Comparison at Davos, Switzerland (Reda, 1996). Between 3 and 6 July 1997, the UW-CNR1 four-way radiometer was set up about $30 \mathrm{~m}$ from the ARM radiometers at the ARM Central Facility (CF01); 30 min averaged data from both sets of instruments were compared. The slope of the solar radiation comparison was 1.044 during the daytime; with this slope difference removed, the RMS difference between the UW-CNR1 
and the ARM pyranometer was $10 \mathrm{~W} \mathrm{~m}^{-2}$ on an average solar flux density of $587 \mathrm{~W} \mathrm{~m}^{-2}(1.7 \%)$.

The second issue of spatial sampling is difficult to address in a general way because it depends on the characteristics of the sites. Although the downward-facing UW-CNR1 pyranometer was about $30 \mathrm{~m}$ from the ARM downward-facing pyranometer, the albedo from the two instruments was within 0.002 or $1 \%$ relative difference. The uniformity of the various sites used for radiation comparisons was excellent; particularly the ER01 site in El Reno, OK, where most of the net radiometer and eddy-covariance flux comparisons took place. Because pyranometers can be matched to a fraction of a percent, the absolute error in the net solar radiation is less than $3 \%$; therefore, the final absolute error associated with the UW-CNR1 net solar radiation measurement is less than $3 \%$ with a $1.7 \%$ random error.

The ARM thermal radiation measurements of sky and ground fluxes are made with pyrgeometers that are matched to reference pyrgeometers at the National Oceanic and Atmospheric Administration (NOAA) to insure 3-5\% consistency. Although no absolute standards exist for pyrgeometers, the measurements done at the ARM sites are done as carefully as any in the world. The most difficult thermal measurement is the sky thermal flux density, because of the nonuniformity of the sky emission versus zenith angle and nonuniform heating of the pyrgeometer domes by the sun. The upward-facing ARM pyrgeometers are shaded from the sun by an occulting disk on an equitorial mount to minimize heating of the dome by the sun; a precaution rarely taken by scientists monitoring sky thermal fluxes. A comparison between the UW-CNR1 pyrgeometer and the ARM pyrgeometer between 3 and 7 July 1997 revealed that the UW-CNR1 upward-facing pyrgeometer has an average daytime bias of $+7 \mathrm{~W} \mathrm{~m}^{-2}(2 \%)$. Under night-time conditions, the UW-CNR1 pyrgeometer measures a surface emission flux density about $2 \mathrm{~W} \mathrm{~m}^{-2}$ less than the ARM pyrgeometer $(<1 \%)$. The larger bias during daytime confirms the importance of solar heating on the upper surface of the unshaded UW-CNR1 pyrgeometer. The graph of the downward-facing UW-CNR1 pyrgeometer against the ARM downward-facing pyrgeometer yielded a slope of 0.999 and a standard error about the regression line of $2 \mathrm{~W} \mathrm{~m}^{-2}(0.5 \%)$. The agreement between the thermal radiation measurements from the UW-CNR1 pyrgeometers and the ARM pyrgeometers is very encouraging because the ARM pyrgeometers are from Eppley Instruments in the US and the UW-CNR1 is from Kipp and Zonen in Holland; clearly these two companies have independent calibration references. Furthermore, the CNR1 has a flat upper surface that is not cosine corrected while the ARM Eppley instruments have domes with cosine correction; in spite of this, the agreement is excellent. The pyrgeometer measurements from the UW-CNR1 four-way radiometer were not adjusted in any way for the comparison with other net radiometers used in the SGP97 experiment. Because pyrgeometers can be matched with each other better than they can be calibrated to known absolute accuracy, the error in net thermal flux density $\left(\mathrm{W} \mathrm{m}^{-2}\right)$ should only be slightly larger than the error in the unidirectional flux density.

The overall accuracy of the net all-wave radiation is a combination of a $3 \%$ absolute error in the net solar radiation and a $15 \%$ error in the net thermal radiation resulting in a $6 \%$ overall accuracy on a net radiation value of about $500 \mathrm{~W} \mathrm{~m}^{-2}$. A plot of the UW-CNR1 versus the ARM net radiation measurements yielded a slope of 1.005 and a standard error about the regression of $10 \mathrm{~W} \mathrm{~m}^{-2}$ after matching the UW-CNR1 solar radiation to the ARM solar radiation. These results are consistent with the detailed comparison study of various net radiometers by Hodges and Smith (1997).

Given the known accuracy of the UW-CNR1 four-way net radiation measurements, other net radiometers used in the SGP97 study were compared to this secondary standard. The data in Fig. 1 are $30 \mathrm{~min}$ averages of $\mathrm{Rn}$ that were taken on different days over the entire experiment period as the UW-CNR1 net radiometer was collocated with other net radiometers. The RMS difference between the various net radiometers and the UW-CNR1 is $22 \mathrm{~W} \mathrm{~m}^{-2}$. The systematic difference between the UW-CNR1 net radiometer and the REBS net radiometers is apparent in Fig. 1; the slope of the regression being 0.96 and the intercept being $25 \mathrm{~W} \mathrm{~m}^{-2}$, with a standard error about the regression of $10 \mathrm{~W} \mathrm{~m}^{-2}$. The thick plastic domes on these net radiometers may have a sufficiently low thermal transmissivity so that incident thermal sky radiation is overestimated by approximately $25 \mathrm{~W} \mathrm{~m}^{-2}$. One net radiometer, (REBS $\mathrm{Q} * 7$ model) had $15 \%$ underestimates of $\mathrm{Rn}$ because of errors in factory 


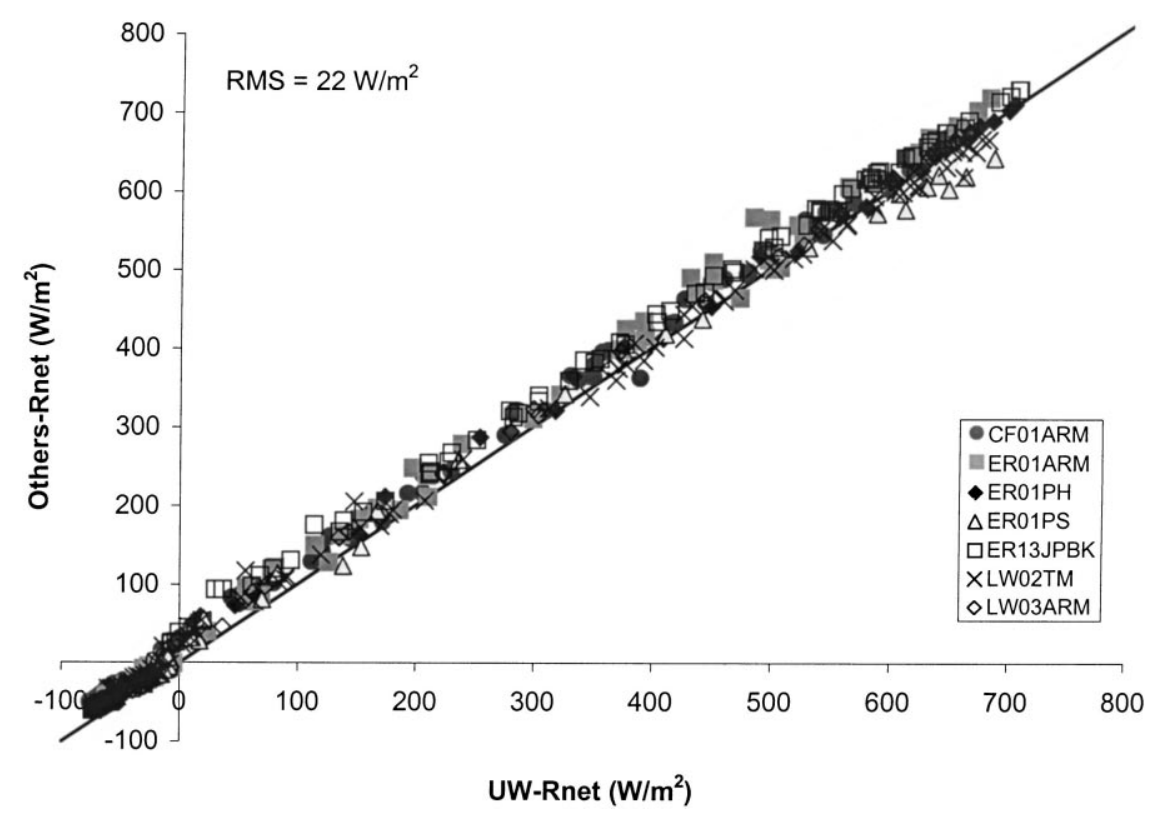

Fig. 1. One-to-one graph of measurements of net radiation from UW-CNR1 Kipp and Zonen net radiometer collocated with other net radiometers after UW-CNR1 has been calibrated with ARM radiation instruments.

calibrations. The other REBS net radiometers agreed well with the UW-CNR1 measurements.

The spatial variability associated with the reflected solar and emitted thermal radiation is also a source of error in net radiation measurements. However, this error should be a random error and not a bias when associated with the numerous sites used in this comparison, so that it is not a reasonable explanation for systematic underestimates of energy-balance closure. At site ER01 two net radiometers were mounted at a height of $2 \mathrm{~m}$ above the ground, separated by a distance of about $100 \mathrm{~m}$, and a third net radiometer mounted at a $10 \mathrm{~m}$ height about $50 \mathrm{~m}$ away from the other two radiometers. All the net radiometers agreed to within $3 \%$ of the mean of the three net-radiometer measurements. Clearly, spatial variability was not a significant problem at site ER01.

\subsubsection{Soil-surface heat-conduction flux}

Measurements of soil-surface heat-conduction flux have uncertainties associated with the accuracy of measurements and spatial variability. The accuracy of the soil heat flux plates was determined by calibrating several of the units in the laboratory (Table 4). The first four plates listed were used in SGP97. The SGP97 heat flux plates under-measured the heat flux by about $6 \%$ with the dry quartz sand. Moisture conditions in the field during SGP97 ranged from field capacity at ER01 after heavy rain to drier conditions at the surface of the bare soil at ER13. However, frequent, heavy rains occurred throughout the SGP97 field experiment at the various flux sites. Conductivity of the soil near the surface could have varied from 0.5 to $1.3 \mathrm{~W} \mathrm{~m}^{-1} \mathrm{~K}^{-1}$ during the field experiment, which is near the conductivity of the quartz sand in

Table 4

Soil heat flux plate calibration in dry quartz sand expressed as percent difference between measured soil heat flux and reference flux for each plate

\begin{tabular}{lllllllll}
\hline Plate & R1 $(\%)^{\mathrm{a}}$ & $\mathrm{R} 2(\%)$ & $\mathrm{R} 3(\%)$ & $\mathrm{R} 4(\%)$ & $\mathrm{R} 5(\%)$ & $\mathrm{R} 6(\%)$ & $\mathrm{R} 7(\%)$ & R8 $(\%)$ \\
\hline REBS & -10 & 6 & -9 & -15 & -2 & -2 & -10 & -6
\end{tabular}

${ }^{\text {a }}$ R1 through R4 were REBS HFT-3 plates used at ER01; R5 and R6 were REBS HFT-1; R7 and R8 were REBS HFT-3. 


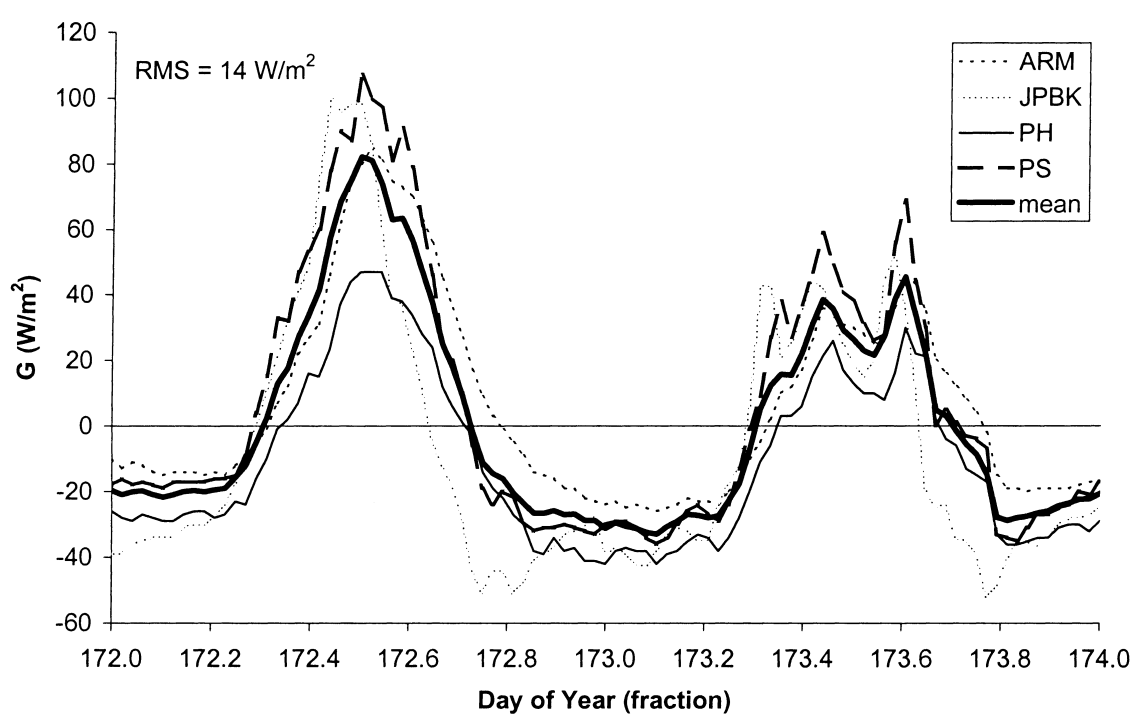

Fig. 2. Time series (30 min averages) of soil surface heat flux from several instrument systems at ER01 on DOY 172-173. Each time series is an average of two to five locations of measurements for a total of 11 locations.

the calibration box $\left(0.77 \mathrm{~W} \mathrm{~m}^{-1} \mathrm{~K}^{-1}\right)$. Therefore, the range in conductivity of the silt loam at the El Reno sites suggests a typical uncertainty of about $5 \%$ in the soil heat flux plate measurement. The uncertainty associated with the heat capacity of the soil layer above the heat flux plate is about $20 \%$ if water content is not measured and a nominal volumetric water content of 0.25 is always used (Campbell and Norman, 1998). Because water content in the top $5 \mathrm{~cm}$ of soil was measured in the SGP97 experiment, this error is reduced to less than $10 \%$. Combining the errors in heat flux plate accuracy and heat storage uncertainties, the probable error in the soil heat flux measurement is $15 \%$ because approximately half the flux density is measured by the heat-flux plate and $1 / 2$ measured by the heat storage change. From the variability of calibration results in Table 4 and the random nature of soil water content errors, these errors in soil heat flux are likely to be random errors and thus are not likely to contribute to a systematic overestimate of available energy across all the sites used in the SGP97 comparison.

The spatial variability of soil-surface heat flux measurements is shown by the time series at site ER01 in Fig. 2 for both a clear day (DOY 172) and a partly cloudy day (DOY 173). Each data value is an average of measurements from at least two soil heat flux plates after adjustment for heat storage between the soil surface and the plate. The phase response of each set of sensors may depend on the overlying surface. The results in Fig. 2 include errors from sensor calibration, soil water content uncertainty and spatial variability, and suggest that the standard error associated with soil heat flux measurement at the ER01 site during flux comparisons was about $14 \mathrm{~W} \mathrm{~m}^{-2}$, or about $15-20 \%$ of a typical daytime soil heat flux. Again, these errors are random errors and should not contribute to systematic biases in the closure of the surface energy balance.

\subsection{Comparisons of eddy-covariance fluxes}

\subsubsection{Latent and sensible heat fluxes}

Results from the comparison of the UW EC system with the USDA-ARS EC systems at ER01, and the comparison of the UW EC system with the USDA-ARS EC system at ER13 are shown in Fig. 3. Latent heat flux was quite consistent among all CSI instruments with an RMS value of $22 \mathrm{~W} \mathrm{~m}^{-2}$. Likewise, the sensible heat flux compared well with an RMS value of $15 \mathrm{~W} \mathrm{~m}^{-2}$, although a bias does appear to be present. 

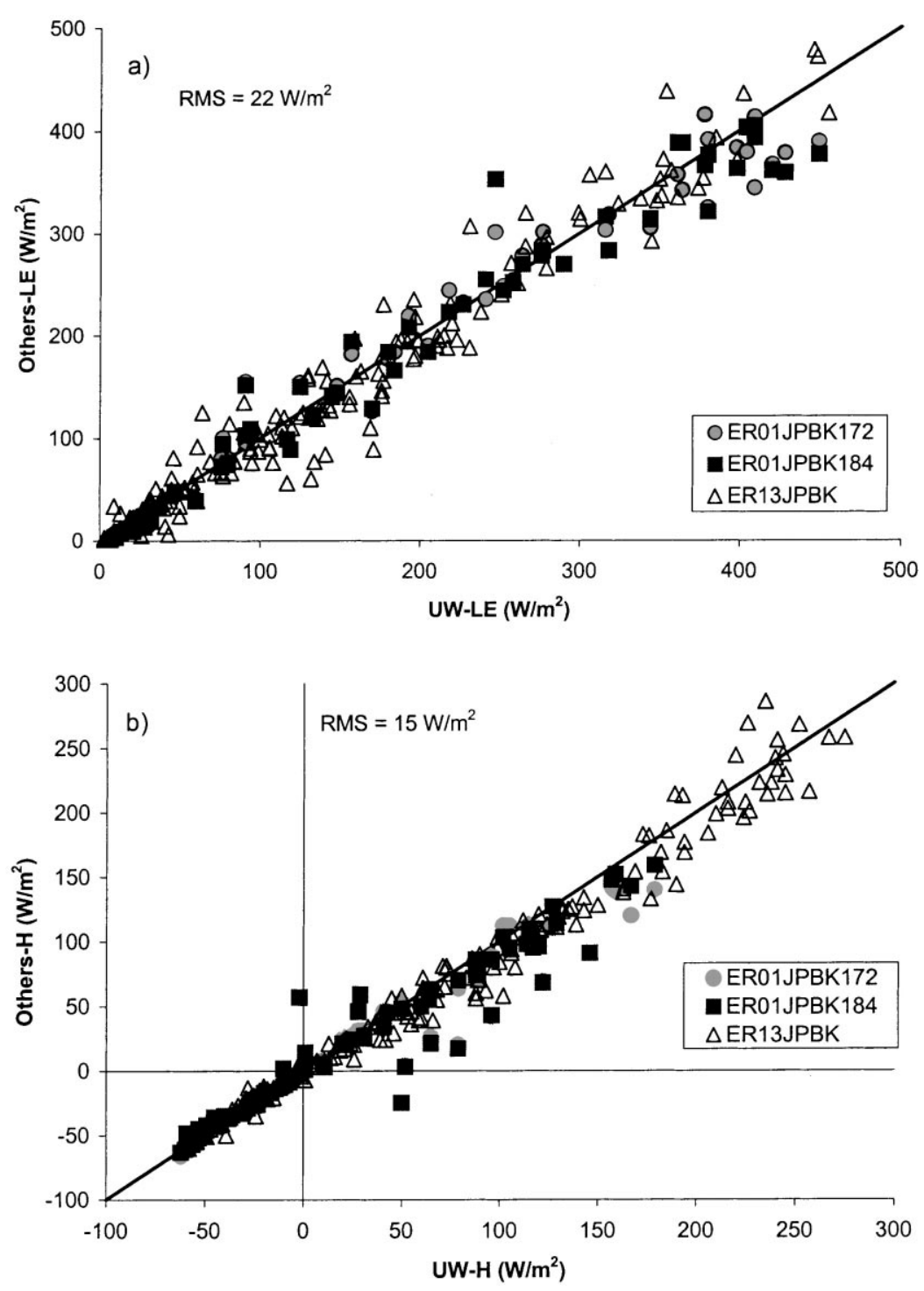

Fig. 3. One-to-one graph of EC system comparison between UW Campbell Scientific (CSI) type and other CSI type systems: (a) latent heat flux (LE) measurements, and (b) sensible heat flux $(H)$ measurements.

Results from the comparison of the UW EC system with three non-CSI (Mixed) types of eddy-covariance systems are shown in Fig. 4. The RMS value of $38 \mathrm{~W} \mathrm{~m}^{-2}$ for LE is larger than that for the CSI comparison. The CF02ARM system agreed with the UW EC system as well as with the CSI types, but the LW02TM system usually measured a lower latent heat flux and a slightly larger sensible heat flux than the UW EC system. All the CSI and non-CSI systems produced comparable measurements of sensible heat flux with an RMS uncertainty of $21 \mathrm{~W} \mathrm{~m}^{-2}$. Sensible heat flux from $\mathrm{CF} 02 \mathrm{PH}$ is compared to the $\mathrm{UW} \mathrm{H}$ in Fig. 4b, although CF02PH LE is not compared in Fig. 4a. CF02PH used a closed-path infrared gas analyzer to determine LE values, which appeared inaccurate because of problems with calibration. Therefore, only $\mathrm{Rn}, H$, and $G$ measurements will be compared from this system. The measured Bowen-ratios from all EC 

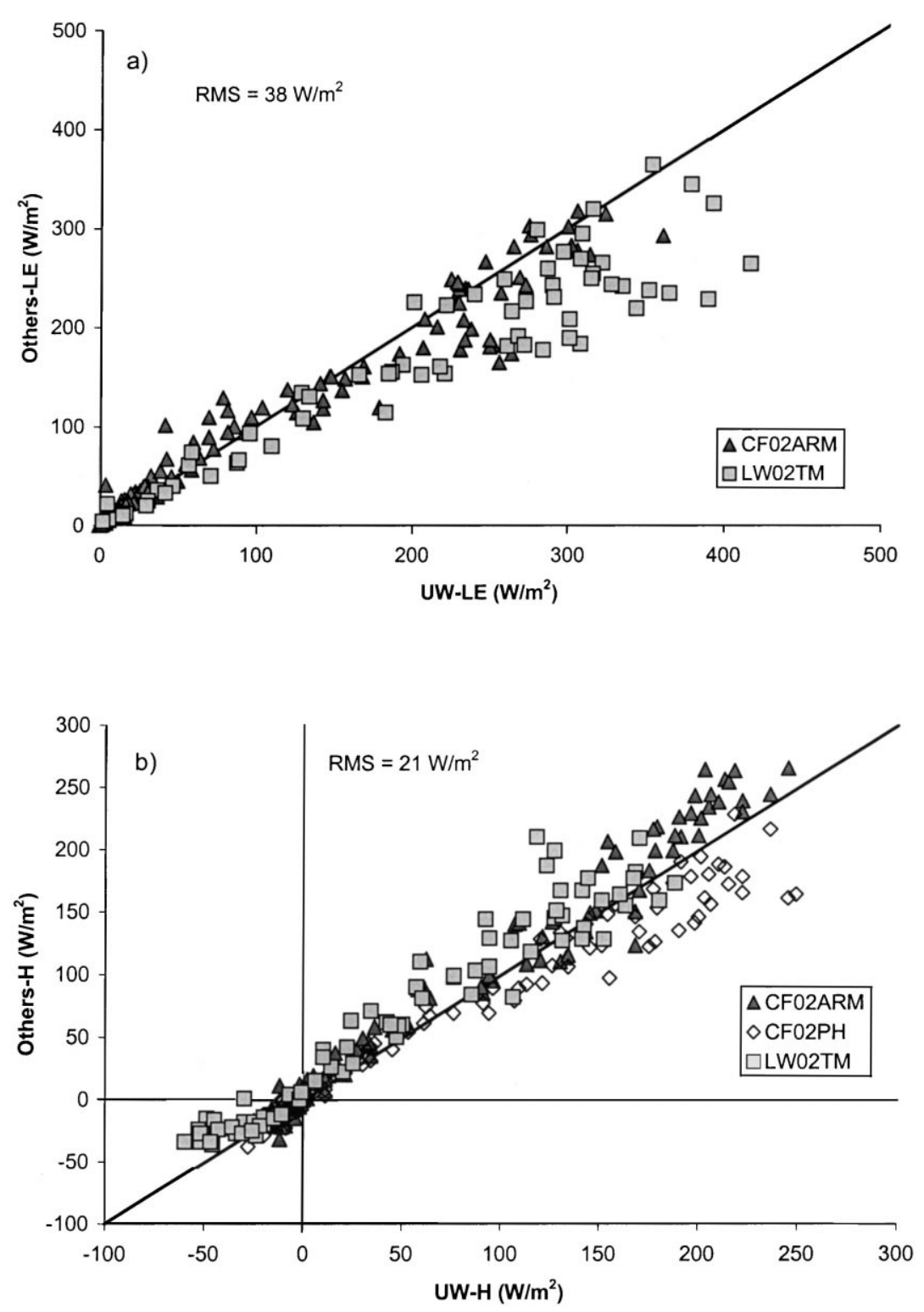

Fig. 4. One-to-one graph of EC system comparison between UW CSI type and non-CSI (mixed) type systems: (a) LE measurements, and (b) $H$ measurements.

systems from 1000 to $1500 \mathrm{CST}$ are compared in Fig. 5. Like the LE and $H$ comparison, Bowen-ratios compared better among the CSI type instruments while LW02TM showed the poorest correlation. The overall standard deviation for the Bowen-ratio comparison of all EC systems is 0.18 for Bowen-ratio values that varied from 0.1 to 2 .

\subsubsection{Energy-balance closure}

During the SGP97 experiment, all eddy-covariance systems attained closure of the energy budget of between 70 and $90 \%$ for $30 \mathrm{~min}$ averaged values. Closure rates can be seen in Table 5, which lists each EC system plus the UW EC system when it was located at that site. Table 5 shows the closure 


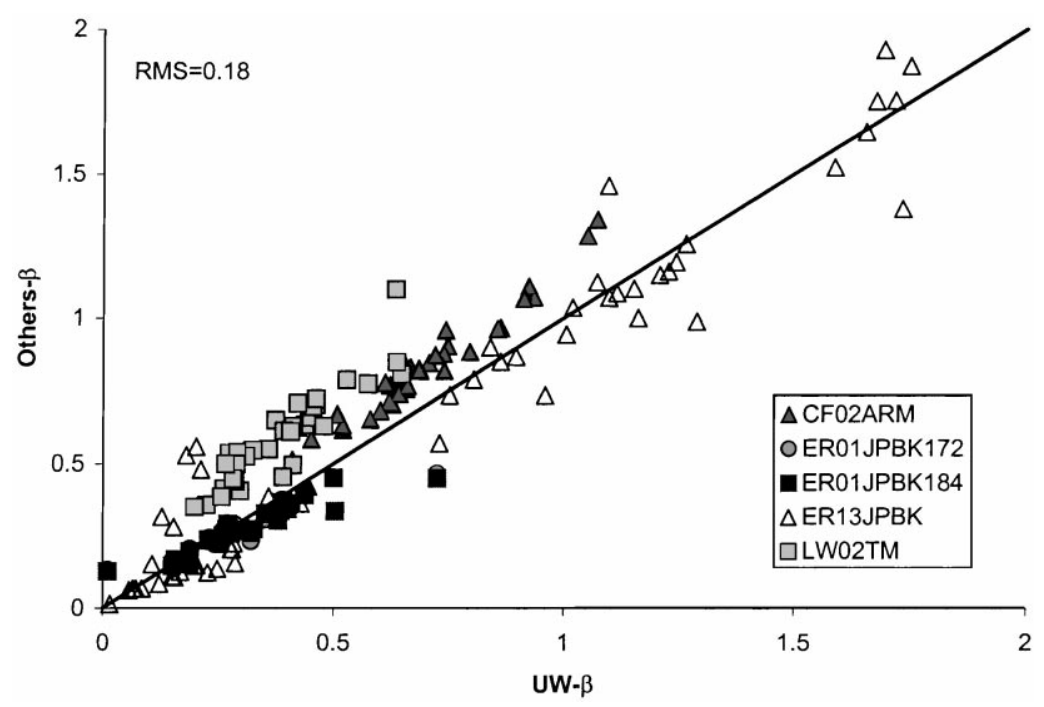

Fig. 5. One-to-one graph comparing midday Bowen-ratios $(\beta)(1000-1500$ CST) measured by the UW CSI system with Bowen-ratios measured by all other types of EC systems.

rate based on 30 min flux averages and sunrise to sunset average flux values. Sunrise to sunset average flux closure rates were usually slightly greater than the $30 \mathrm{~min}$ values, but in some cases they were equal or smaller. These results are somewhat different from those found by Mahrt (1998), who determined that $24 \mathrm{~h}$ average fluxes from towers in BOREAS attained better closure than midday values of fluxes.

Closure of ER13JPBK was near $80 \%$ during the experiment period (June and July), but increased to about $90 \%$ under very dry conditions in August. In-

Table 5

Closure rates of various systems from $30 \mathrm{~min}$ flux averages and fluxes averaged from sunrise to sunset

\begin{tabular}{lll}
\hline SITE ID & $30 \min (\%)$ & Sunrise/Set \\
\hline CF02ARM & 78 & 78 \\
CF02UW & 72 & 80 \\
ER01JPBK & 75 & 79 \\
ER05JPBK & 77 & 80 \\
ER09JPBK & 75 & 75 \\
ER13JPBK & 78 & 83 \\
ER13UW & 91 & 87 \\
LW02TM & 71 & 77 \\
LW02UW & 77 & 84 \\
\hline
\end{tabular}

creased closure rates at very dry sites may imply accurate sensible heat flux measurement or latent heat flux measurement errors; possible evidence for forcing closure by calculating the latent heat flux as a residual of the energy budget. However, at this site, it cannot be assumed that sensible heat flux was measured more accurately than latent heat flux because the energy budget did not result in an average value of $D$ near unity.

Uncertainty in available energy cannot account for the lack of closure, which is systematically low by $100-150 \mathrm{~W} \mathrm{~m}^{-2}$ at midday. The accuracy of the net radiation measurements could contribute a systematic error of $35 \mathrm{~W} \mathrm{~m}^{-2}$, or $6 \%$ of the typical midday net radiation of $600 \mathrm{~W} \mathrm{~m}^{-2} ; 7 \%$ of the available energy. The error in soil heat conduction flux could contribute another $15 \mathrm{~W} \mathrm{~m}^{-2}$ of error to the available energy. Even though this soil heat conduction error should be random and not contribute to the systematic error in closure, including it increases the error in available energy to $10 \%$ and still only accounts for half of the $130 \mathrm{~W} \mathrm{~m}^{-2}$ shortfall in closure. Clearly the problem with energy-balance closure at this grass site in Oklahoma is not caused by errors in the available energy. Therefore, forcing closure of the surface energy budget is most reasonably accomplished by adjusting the eddy-covariance fluxes. 


\subsubsection{Forcing closure}

Two methods for forcing energy-balance closure, that is assuring conservation of energy for the eddy-covariance measurements, are the following: (1) calculating the LE flux as a residual of the surface energy budget and (2) assuming the Bowen-ratio is measured accurately by the eddy-covariance system and adjusting both LE and $H$ to preserve the Bowen-ratio and conserve energy.

Fig. 6 shows latent heat flux values from all eddy-covariance systems (CSI and Mixed types) during daylight hours $\left(\mathrm{Rn}>50 \mathrm{~W} \mathrm{~m}^{-2}\right)$ after the energy budget has been closed by estimating the latent heat flux as the residual of the surface energy budget and ignoring the latent heat flux measurements. The scatter seen in Fig. 4a has decreased with this method and contributes to the total standard deviation of $23 \mathrm{~W} \mathrm{~m}^{-2}$. The bias toward low LE values from the LW02TM system seen in Fig. 4a has been eliminated. CF02PH LE values appear here since LE measurements were not used in this comparison. It was possible to close the energy budget for this sys- tem since only values of $\mathrm{Rn}, H$, and $G$ were used in this method of closure.

Fig. 7 shows LE and $H$ during daylight hours assuming that energy was correctly partitioned into the Bowen-ratio, although values of $H$ and LE may have been under-measured. This closure method resulted in an RMS value of $22 \mathrm{~W} \mathrm{~m}^{-2}$ for $\mathrm{LE}$, which is not statistically different from closing the energy budget with residual LE (Fig. 6), although LW02TM values retain the low bias seen in Fig. 4a.

Both the methods for closing the measured surface energy budget give similar results. However, discarding the measurements of LE seems to be unjustified. The Krypton hygrometer used in all CSI systems compared very well to a Li-Cor LI-6262 closed-path infrared gas analyzer in an independent comparison (Sauer et al., 1995). Therefore, the second method of closing the energy balance by preserving the Bowen-ratio seems to be logically preferred. Furthermore, Fitzjarrald and Moore (1994) suggested that closing the energy budget using the residual-LE method may not be as accurate as using Bowen-ratio

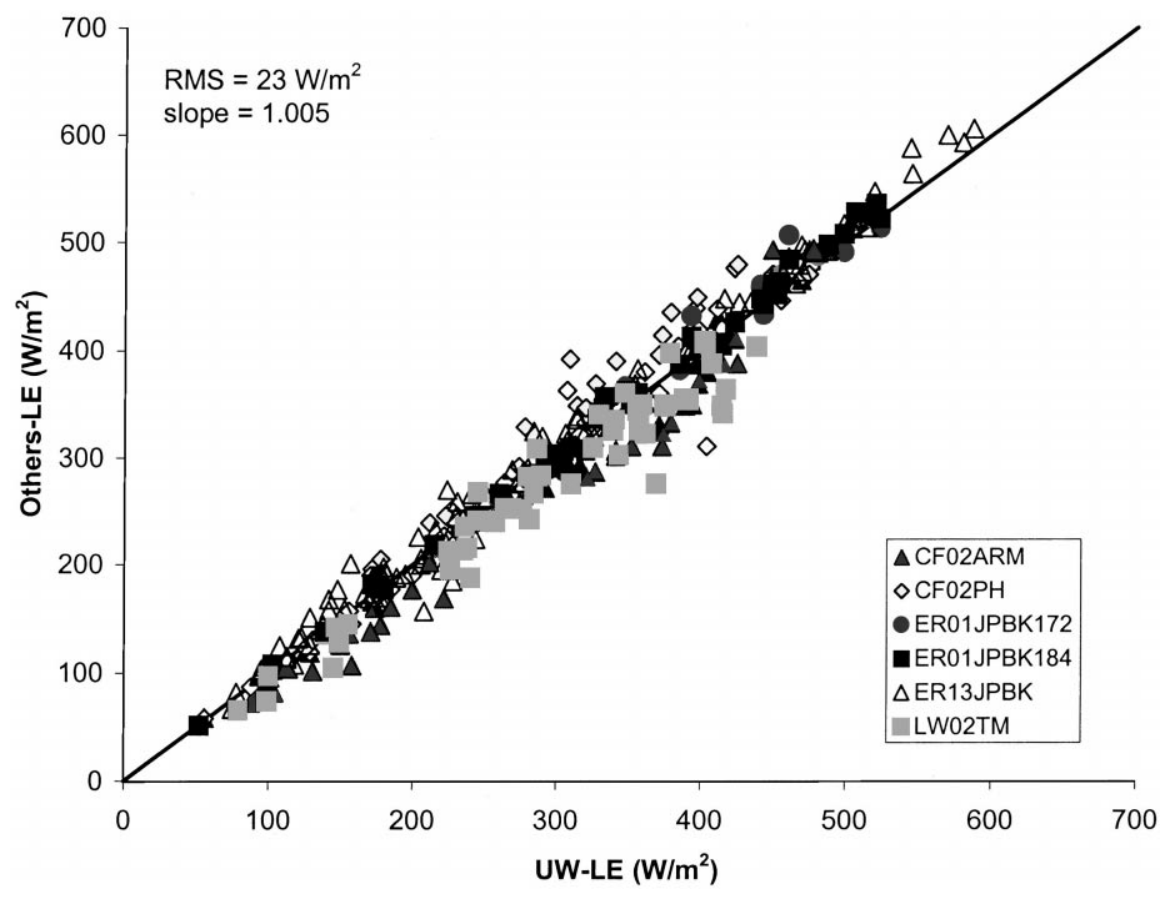

Fig. 6. Comparison of LE estimates from the UW EC system with LE estimates from other EC systems after applying residual LE closure to the energy budget. All LE estimates were obtained as a residual from the surface energy balance using measured values of Rn, $G$, and $H$. 

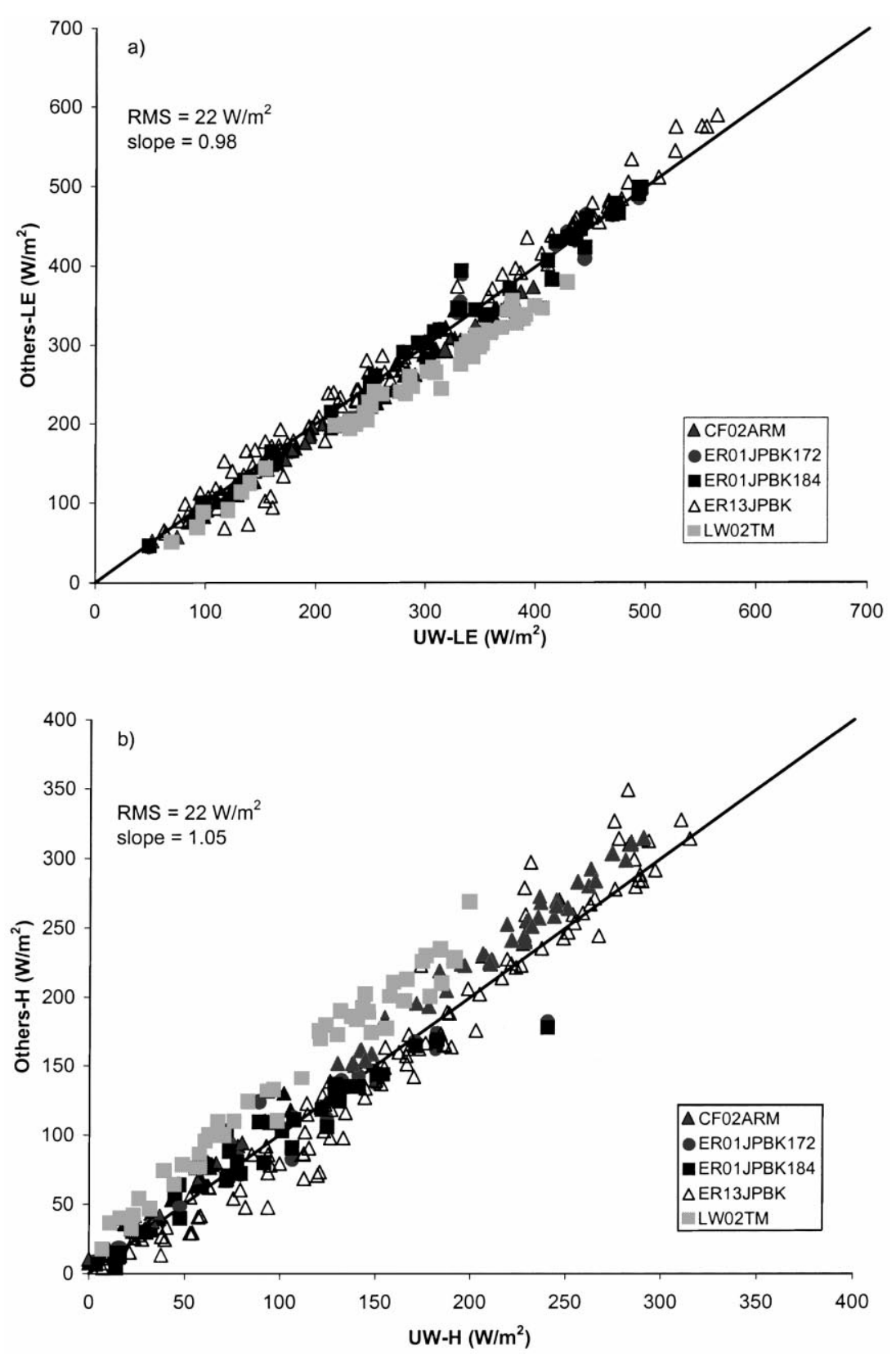

Fig. 7. Comparison of (a) LE, and (b) $H$ fluxes from the UW EC system with fluxes from other EC systems after closure using measured Bowen-ratio.

closure because of uncertainties in the value and phase of $G$.

Another way to evaluate the preferred method for closing the measured energy budget may be to compare eddy-covariance measurements to EBBR mea- surements. EBBR measurements assume conservation of energy to solve for $H$ and LE so eddy-covariance measurements must satisfy conservation of energy for meaningful comparisons with EBBR measurements. Table 6 contains results from a comparison of fluxes 
Table 6

Comparison of LE and $\mathrm{H}$ from UW EC measurements with three EBBR measurement systems at two sites using two closure methods for the UW EC system. The slope of the regression (forced through the origin) of each EBBR flux measurement against the adjusted UW EC flux and the standard error about the regression line are tabulated

\begin{tabular}{lllll}
\hline & \multicolumn{2}{l}{ UW EC closed with residual-LE method } & & \multicolumn{2}{c}{ UW EC closed with Bowen-ratio method } \\
\cline { 2 - 4 } & Slope & Standard error $\left(\mathrm{W} \mathrm{m}^{-2}\right)$ & & Slope \\
\hline LE ER01ARM & 1.14 & 29 & 1.17 & 26 \\
LE ER01PS & 0.85 & 17 & 0.84 & 22 \\
LE LW03ARM & 0.83 & 36 & 0.99 & 13 \\
H ER01ARM & 0.51 & 26 & 0.47 & 24 \\
H ER01PS & 0.91 & 18 & 0.93 & 22 \\
H LW03ARM & 1.23 & 48 & 1.01 & 13 \\
\hline
\end{tabular}

from three EBBR systems at two sites with the UW EC system. The slope of a 1:1 regression (adjusted UW EC fluxes on abcissa) and the standard error about the regression line are included for both closure assumptions of the UW EC system for both LE and $H$. The results in Table 6 do not demonstrate a clear advantage for either closure method. However, the Bowen-ratio closure method agrees more closely with the EBBR measurements for the LW03ARM system, which clearly had the largest sensible heat fluxes $\left(300 \mathrm{~W} \mathrm{~m}^{-2}\right.$ for LW03ARM versus $100 \mathrm{~W} \mathrm{~m}^{-2}$ for ER01ARM and ER01PS) and may thus represent the best test with the lowest EBBR measurement errors. Because of the large disagreement between ER01ARM fluxes of $H$ and other measurements, the results are less conclusive than desirable. However, the flux of $\mathrm{H}$ from ER01ARM does not agree with the UW EC flux of $H$ regardless of the closure method used. A small error in the temperature gradient measurement at ER01ARM (approximately 0.1-0.2 C) could account for this disagreement because of small fluxes of $H$; however, the actual reason for this discrepancy is unknown.

\subsection{Implications for $\mathrm{CO}_{2}$ fluxes}

The lack of closure of the surface energy budget alerts us to the possibility that eddy-covariance flux measurements may be underestimates of the actual fluxes. With other fluxes, such as $\mathrm{CO}_{2}$ or momentum, applying a conservation principle to check the validity of the fluxes is not practical. If the underestimation of eddy covariance fluxes arises from a fundamental process, such as point measurements not accommodating dispersive fluxes or covariance measurements along the direction of the mean wind missing some of the total covariance, then we might expect the underestimates to carry over to other fluxes because of similarity among fluxes. The relationship between the underestimation of evaporation flux and the possible underestimation of $\mathrm{CO}_{2}$ flux can be investigated by determining both fluxes with several independent methods: (1) Direct measurement using eddy covariance instruments, (2) direct measurement with conditional sampling, (3) measurement by energy-balance-Bowen-ratio method combined with $\mathrm{CO}_{2}$ concentration gradient $\left(\mathrm{EBBR} / \mathrm{CO}_{2}\right)$ and (4) estimation by combining the scaling of leaf measurements to the canopy with soil-surface measurements of $\mathrm{CO}_{2}$ flux. Such an experiment was done at Lincoln, NE on 15-18 July, 1992 over sorghum.

The sorghum canopy was $0.9 \mathrm{~m}$ tall with a leaf area index (LAI) of 4.0 and the soil was very wet from a large amount of rain the previous week. Typical wind speeds varied from 3 to $8 \mathrm{~m} \mathrm{~s}^{-1}$ during the measurements and the typical ratio of fetch to measurement height (height of instruments above canopy displacement height) varied from 100 to 400 . The eddy covariance wind and temperature measurements were made at a height of $2.2 \mathrm{~m}(1.5 \mathrm{~m}$ above the canopy displacement height) with a Campbell Scientific (CSI, Logan, UT) one-dimensional sonic anemometer, and evaporation and $\mathrm{CO}_{2}$ flux measurements were made using a closed-path method (by J. Norman, T. Wilson) by combining the vertical velocity measurements with gas concentration measurements using a LI-6262 (LICOR, Lincoln, NE) (Sauer et al., 1995). The closed path method used a $3 \mathrm{~m}$ sampling tube, a $101 / \mathrm{min}$ flow rate, and temperature and 
pressure measurements within the infrared-gas-analyzer sampling cell, which were monitored for later corrections. The various corrections to the water vapor and $\mathrm{CO}_{2}$ fluxes, including Webb-Pearman, sensor spacing and tube-damping corrections, typically were about 20\%. The conditional-sampling measurements (by J. Baker) were made at a height of $2.5 \mathrm{~m}$ with the same instruments as those used for eddy-covariance measurements (Baker et al., 1992). Eddy covariance heat and water vapor measurements (without $\mathrm{CO}_{2}$ measurements) were made at a height of $2.2 \mathrm{~m}$ using two CSI one-dimensional sonic anemometers and krypton hygrometers (by B. Tanner, J. Green and E. Swaitek). The eddy-covariance krypton hygrometer measurements (corrected for Webb-Pearman effects) agreed reasonably with the corrected, closed-path (LI-6262) measurements (mean difference in LE over all measurements was $10 \mathrm{~W} \mathrm{~m}^{-2}$ ). $\mathrm{EBBR} / \mathrm{CO}_{2}$ measurements of heat, water vapor, and $\mathrm{CO}_{2}$ fluxes were made at two locations with CSI equipment (by B. Tanner, J. Green and E. Swaitek) with lower sampling at $1.7 \mathrm{~m}$ and upper sampling at $2.5 \mathrm{~m}$. Net radiation was measured at two locations (by J. Baker and B. Tanner) with instruments from two manufacturers that agreed within about $20 \mathrm{~W} \mathrm{~m}^{-2}$. Soil heat flux was measured at four locations at a depth of $0.08 \mathrm{~m}$ with temperature measurements at 0.02 and $0.06 \mathrm{~m}$. Leaf physiological measurements (leaf photosynthetic rate and stomatal conductance) for scaling were made through out the experiment with LI-6200 (LICOR, Lincoln, NE) gas exchange systems (by J. Welles, D. McDermitt and K. Peterson). Soil-surface measurements of $\mathrm{CO}_{2}$ fluxes also were made during the experiment with the LI-6200 (by T. Arkebauer, P. Mielnick, K. Leapley, and D. Lathrop) to adjust scaled photosynthesis measurements for surface fluxes to match micrometeorological measurements. The scaling method is described in Norman et al. (1992) and incorporates effects of light interception, atmospheric humidity, wind speed and $\mathrm{CO}_{2}$ concentration. In addition, the scaling approach includes the effect of a leaf boundary-layer resistance in the LI-6200 chamber being lower than the boundary-layer resistance on leaves in the field.

The ratio of eddy-covariance $\mathrm{CO}_{2}$ flux to EBBR $\mathrm{CO}_{2}$ flux and the ratio of eddy-covariance $\mathrm{CO}_{2}$ flux to the scaled-leaf $\mathrm{CO}_{2}$ flux are plotted against the closure fraction (D) in Fig. 8. Each data value in Fig. 8 corresponds to a $30 \mathrm{~min}$ average when the wind was from a direction that provided adequate fetch (100:1-400:1). Similar ratios are plotted for the

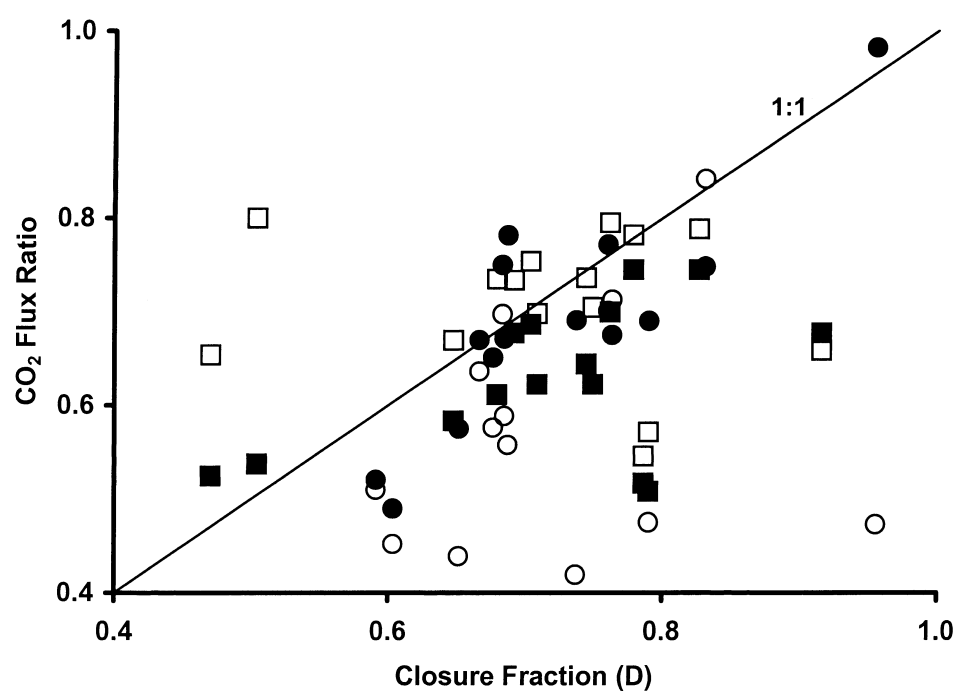

Fig. 8. Four flux ratios are plotted against the closure fraction based on 30 min measurements: (1) $\mathrm{The}$ ratio of $\mathrm{CO}_{2}$ flux measured by conditional sampling to scaled-leaf $\mathrm{CO}_{2}$ flux (open squares), (2) the ratio of $\mathrm{CO}_{2}$ flux measured by conditional sampling to $\mathrm{CO} 2$ flux measured by EBBR with $\mathrm{CO}_{2}$ concentration gradient (solid squares), (3) the ratio of $\mathrm{CO}_{2}$ flux measured by eddy-covariance to scaled-leaf $\mathrm{CO}_{2}$ flux (open circles) and (4) the ratio of $\mathrm{CO}_{2}$ flux measured by eddy-covariance to $\mathrm{CO}_{2}$ flux measured by EBBR with $\mathrm{CO} 2$ concentration gradient (solid circles). The 1:1 line corresponds to the condition that $\mathrm{CO}_{2}$ flux is underestimated by the same amount as evaporation flux. 
conditional-sampling fluxes (Fig. 8). The $\mathrm{CO}_{2}$ flux ratios that fall along the 1:1 line in Fig. 8 indicate that eddy-covariance $\mathrm{CO}_{2}$ fluxes are underestimated by the same fraction as eddy covariance evaporation fluxes. Clearly the flux ratios referenced to the EBBR/ $/ \mathrm{CO}_{2}$ measurements (dark symbols in Fig. 8) show that $\mathrm{CO}_{2}$ fluxes measured with eddy covariance and conditional sampling instruments are underestimated by the same factor as measured energy fluxes. The scaled-leaf estimates of $\mathrm{CO}_{2}$ flux are completely independent of any micrometeorological flux measurements and thus represent a truly independent test of the closure effect on $\mathrm{CO}_{2}$ fluxes. Although the $\mathrm{CO}_{2}$ flux ratios referenced to the scaled-leaf estimates (open symbols in Fig. 8) show more scatter than $\mathrm{CO}_{2}$ flux ratios referenced to $\mathrm{EBBR} / \mathrm{CO}_{2}$ measurements, the results show that eddy-covariance and conditional sampling measurements of $\mathrm{CO}_{2}$ fluxes are underestimated by comparable fractions to the water vapor flux under-measurements. Clearly these results support the similarity of measured, eddy-covariance, $\mathrm{CO}_{2}$ and water vapor fluxes; namely, that $\mathrm{CO}_{2}$ fluxes are underestimated by an amount similar to water vapor fluxes when energy-balance closure is not achieved.

\section{Concluding remarks}

Energy into and out of a region of measurement must be conserved, but eddy-covariance systems do not always satisfy conservation of energy. Surface fluxes can be under-measured for a number of reasons including mismatched sources of LE and $H$, inhomogeneous surface cover and soil characteristics, flux divergence or dispersion, non-stationarity of the flow, lack of a fully developed turbulent surface layer, flow distortion, sensor separation, topography and instrument error.

During the Southern Great Plains 1997 Hydrology Experiment, eddy-covariance systems appeared to under-measure $\mathrm{LE}$ and $\mathrm{H}$ fluxes systematically by $10-30 \%$. The accuracy of net radiation measurements was shown to be $6 \%$ of the midday, clear sky, mid-season fluxes. The random errors in spatial sampling of reflected solar and emitted thermal radiation and random errors in soil heat flux should not produce systematic biases in closure over the four different sites involved. Thus the consistent shortfall in LE and $H$ fluxes from eddy-covariance measurements at all sites with all instruments is most likely to be associated with the eddy-covariance measurements themselves and not net radiation and soil heat flux measurements. Even if all the random errors in net radiation and soil heat flux are included as errors in the available energy $(\mathrm{Rn}-G)$, these errors represent only about $1 / 2$ of the shortfall in LE and $H$.

The fetch at ER01, which was much larger than the minimum suggested by Leclerc and Thurtell (1990) and Heilman et al. (1989), and the rain that occurred just before the comparison, provided a near-ideal site for measuring micrometeorological fluxes. Sensor separation did not account for lack of closure as Krypton hygrometers were placed within $10 \mathrm{~cm}$ of the sonic anemometer transducers on all systems so that errors were less than 3\% of the fluxes (Villalobos, 1997). Although UW EC measurements were not coordinate transformed, three other systems in the comparison used coordinate rotations and their closure rates were equal to or less than the UW EC system.

Non-stationarity and flux divergence may be factors in the lack of closure, but they cannot be easily assessed and flux values cannot be easily corrected for this influence. Clearly a variety of factors may prevent the eddy-covariance systems from measuring all the turbulent scales correctly; therefore, the most reasonable assumption is that closure should be forced in order to account for measurement inadequacies. Sensible and latent heat fluxes from the eddy-covariance systems compared best to fluxes from EBBR systems when closure was forced by assuming that eddy-covariance systems accurately partitioned $H$ and LE fluxes into the Bowen-ratio. Furthermore, we see no reason to discard LE measurements as would be required with the residual LE method. This implies that eddy-covariance systems underestimated $H$ and LE in the same proportion. This might also mean that the friction velocity is underestimated - a difficult hypothesis to test. The results from an experiment in Lincoln, NE over sorghum in 1992, which included 13 participants from five institutions, suggest that $\mathrm{CO}_{2}$ flux is undermeasured by the same factor as evapotranspiration flux.

The closure issue becomes even more significant upon consideration of the long-term water balance. Total daytime LE in equivalent millimeters of water, summed over a period of 15 days from four EC 


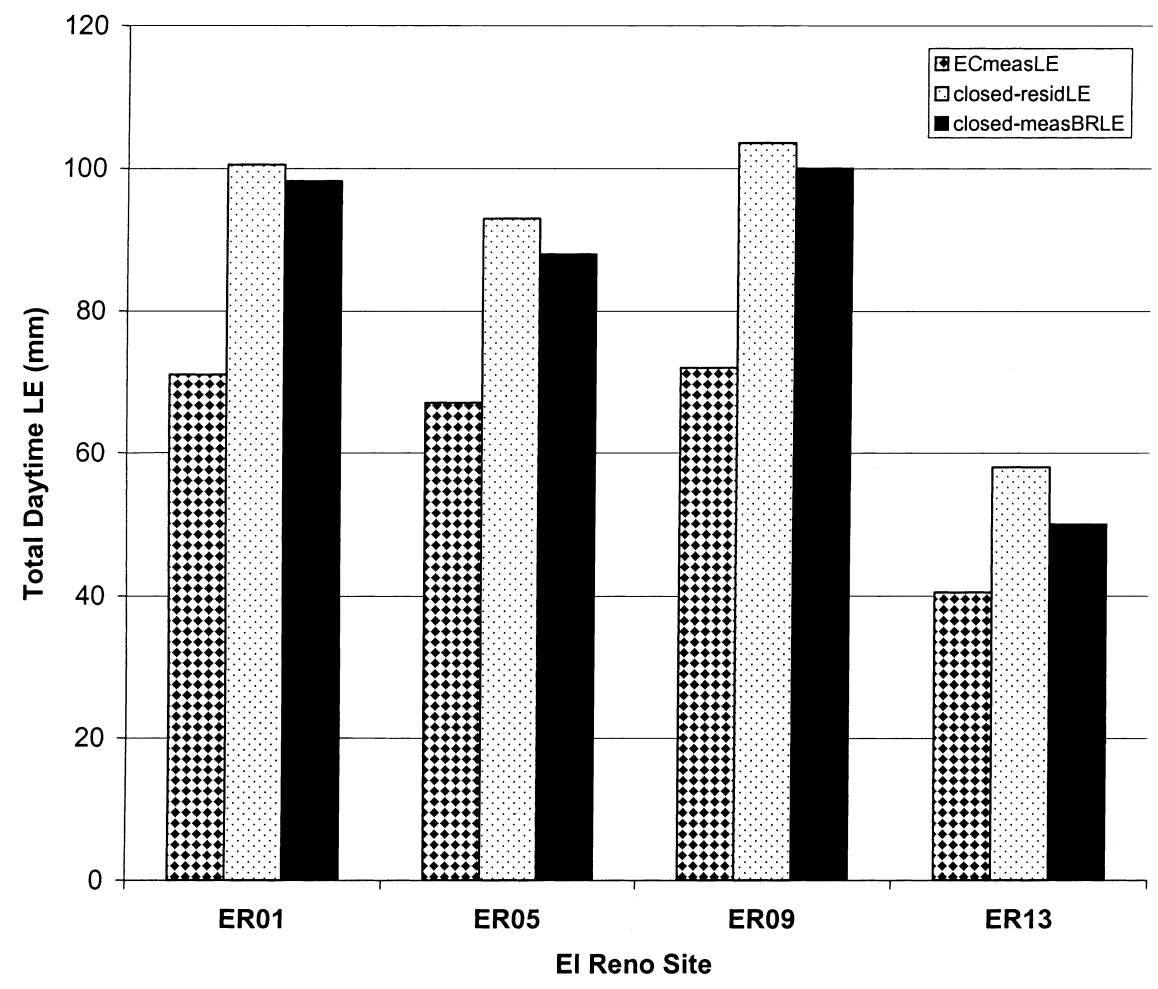

Fig. 9. Total daytime LE in equivalent millimeters of water over DOY 180-195 at the USDA Grazinglands Research Lab measured using the four eddy-covariance systems and calculated after closure of the energy budget according to both suggested methods of closure.

systems, is shown in Fig. 9. The bars show three quantities: (1) The measured LE, (2) LE after closure is forced by calculating LE as the residual to the energy budget and (3) LE after closure is forced using the measured Bowen-ratio. Regardless of the method of closure, differences between measured LE and LE after forcing closure can become significant with time.

For sites that can be treated as relatively homogeneous such that $\mathrm{Rn}-G$ is considered reliable and representative of the eddy covariance flux footprint, our recommendation is to close eddy-covariance energy flux measurements. Since there is no compelling evidence that latent heat flux is under-measured more significantly than the sensible heat flux, the method of closure that assumes the Bowen-ratio is measured accurately is probably most reasonable. Results from this study suggest Bowen-ratio closure is preferred but do not prove it. A record of this closure factor should be maintained with the data so that the original measurements can be easily restored at some date in the future if desirable.

\section{Acknowledgements}

This research was supported by NASA Grant NAGW-4138, USDA Cooperative Agreement No. 58-1270-7-008, and the University of Wisconsin Experiment Station. The authors appreciate the efforts of Dr. Tom Jackson of USDA Hydrology Laboratory in Beltsville, MD for his leadership of the SGP97 experiment.

Jerry L. Hatfield from USDA-ARS National Soil Tilth Laboratory and Tom J. Sauer from USDA-ARS Biomass Research Center provided valuable assistance in the maintenance of the four flux towers operating at the El Reno facility during SGP97. Analyses of ARM Bowen-ratio data were supported by the US Department of Energy under Contract No. W-31-109-Eng-38 as part of the Atmospheric Radiation Measurement Program of the Office of Energy Research, Office of Health and Environmental Research.

Measurements at Lincoln, NE were made by the following: Bert Tanner, Ed Swaitek, and Joel Green 
of Campbell Scientific, Logan, UT; Jon Welles, Dayle McDermitt and Kerry Peterson of LICOR, Lincoln, NE; John Baker of the USDA/ARS, University of Minnesota, St. Paul, MN; Tim Arkebauer, Pat Mielnick, Kevin Leapley, and David Lathrop of the University of Nebraska, Lincoln, NE; John Norman and Tim Wilson, University of Wisconsin, Madison, WI. The measurements were done on the farm of Harry and Raymond Leavitt.

The authors thank the reviewers and editors for their patient and constructive assistance in the refining of this paper.

\section{References}

Adams, R.S., Black, T.A., Fleming, R.L., 1991. Evapotranspiration and surface conductance in a high elevation, grass-covered forest clearcut. Agric. For. Meteorol. 56, 173-193.

Ashktorab, H., Pruitt, W.O., PawU, K.T., George, W.V., 1989. Energy balance determinations close to the soil surface using a micro-Bowen ratio system. Agric. For. Meteorol. 46, 259-274.

Baker, J.M., Norman, J.M., Bland, W.L., 1992. Field scale application of flux measurement by conditional sampling. Agric. For. Meteorol 62, 31-52.

Baldocchi, D., Valentini, R., Running, S., Oechel, W., Dahlman, R., 1996. Strategies for measuring and modeling carbon dioxide and water vapour fluxes over terrestrial ecosystems. Global Change Biol. 2, 159-168.

Barr, A.G., King, K.M., Gillespie, T.J., denHartog, G., Neumann, H.H., 1994. A comparison of Bowen ratio and eddy correlation sensible and latent heat flux measurements above deciduous forest. Boundary-Layer Meteorol. 71, 21-41.

Blanken, P.D., Black, T.A., Yang, P.C., Newmann, H.H., Nesic, Z., Staebler, R., denHartog, G., Novak, M.D., Lee, X., 1997. Energy balance and canopy conductance of a boreal aspen forest: partitioning overstory and understory components. J. Geophys. Res. 102 (D24), 28915-28928.

BORCAL, 1997. Broadband outdoor radiometer calibration report, 14-31 July 1997, Atmospheric Radiation Measurement Archive, Calibration Facility, Southern Great Plains.

Campbell, G.S., Norman, J.M., 1998. Introduction To Environmental Biophysics. Springer, New York.

Dabberdt, W.F., Lenschow, D.H., Horst, T.W., Zimmerman, P.R., Oncley, S.P., Delany, A.C., 1993. Atmosphere-surface exchange measurements. Science 260, 1472-1481.

Dugas, W.A., Fritschen, L.J., Gay, L.W., Held, A.A., Matthias, A.D., Reicosky, D.C., Steduto, P., Steiner, J.L., 1991. Bowen ratio, eddy correlation, and portable chamber measurements of sensible and latent heat flux over irrigated spring wheat. Agric. For. Meteorol. 56, 1-20.

Field, R.T., Fritschen, L.J., Kanemasu, E.T., Smith, E.A., Stewart, J.B., Verma, S.B., Kustas, W.P., 1992. Calibration, comparison, and correction of net radiation instruments used during FIFE. J. Geophys. Res. 97 (D17), 18681-18695.
Fitzjarrald, D.R., Moore, K.E., 1994. Growing season boundary layer climate and surface exchanges in a subarctic lichen woodland. J. Geophys. Res. 99 (D1), 1899-1917.

Fritschen, L.J., Qian, P., Kanemasu, E.T., Nie, D., Smith, E.A., Stewart, J.B., Verma, S.B., Wesely, M.L., 1992. Comparisons of surface flux measurement systems used in FIFE 1989. J. Geophys. Res. 97 (D17), 18697-18713.

Goulden, M.L., Daube, B.C., Fan, S.M., Sutton, D.J., Bazzaz, A., Munger, J.W., Wofsy, S.C., 1997. Physiological responses of a black spruce forest to weather. J. Geophys. Res. 102 (D24), 28987-28996.

Goulden, M.L., Wofsy, S.C., Harden, J.W., Trumbore, S.E., Crill, P.M., Gower, S.T., Fires, T., Daube, B.C., Fan, S.M., Sutton, D.J., Bassas, A., Munger, J.W., 1998. Sensitivity of boreal forest carbon balance to soil thaw. Science 279, 214-217.

Halldin, S., Lindroth, A., 1992. Errors in net radiometry: comparison and evaluation of six radiometer designs. J. Atmos. Oceanic. Technol. 9, 762-783.

Heilman, J.L., Brittin, C.L., Neale, C.M.U., 1989. Fetch requirements for Bowen ratio measurements of latent and sensible heat fluxes. Agric. For. Meteorol. 44, 261-273.

Hodges, G.B., Smith, E.A., 1997. Intercalibration, objective analysis, intercomparison and synthesis of BOREAS surface net radiation measurements. J. Geophys. Res. 102 (D24), 28885-28900.

Jackson, T., 1997. Experiment plan: Southern Great Plains 1997 (SGP97) Hydrology Experiment, USDA-ARS Hydrology Laboratory, Beltsville, MD.

Jarvis, P.G., Massheder, J.M., Hale, S.E., Moncrieff, J.B., Rayment, M., Scott, S.L., 1997. Seasonal variation of carbon dioxide, water vapor, and energy exchanges of a boreal black spruce forest. J. Geophys. Res. 102 (D24), 28953-28966.

Katul, G., Hsieh, C.-I., Bowling, D., Clark, K., Shurpali, N., Turnipseed, A., Albertson, J., Tu, K., Hollinger, D., Evans, B., Offerle, B., Anderson, D., Ellsworth, D., Vogel, C., Oren, R., 1999. Spatial variability of turbulent fluxes in the roughness sublayer of an even-aged pine forest. Boundary-Layer Meteorol. 93, $1-28$

Kustas, W.P., Goodrich, D.C., Moran, M.S., Amer, S.A., Bach, L.B., Blanford, J.H., Chehbouni, A., Claassen, H., Clements, W.E., Doraiswamy, P.C., Dubois, P., Clarke, T.R., Daughtry, C.S.T., Gellman, D.I., Grant, T.A., Hipps, L.E., Huete, A.R., Humes, K.S., Jackson, T.J., Keefer, T.O., Nichols, W.D., Parry, R., Perry, E.M., Pinker, R.T., Pinter, J.P.J., Qi, J., Riggs, A.C., Schmugge, T.J., Shutko, A.M., Stannard, D.I., Swiatek, E., vanLeeuwen, J.D., vanZyl, J., Vidal, A., Washburne, J., Weltz, M.A., 1991. An interdisciplinary field study of the energy and water fluxes in the atmosphere-biosphere system over semi-arid rangelands: description and preliminary results. Bull. Am. Meteorol. Soc. 72, 1683-1705.

Kustas, W.P., Prueger, J.R., Humes, K.S., Starks, P.J., 1999 Estimation of surface heat fluxes at field scale using surface layer versus mixed layer atmospheric variables with radiometric temperature observations. J. Appl. Meteorol. 38, 224-238.

Leclerc, M.Y., Thurtell, G.W., 1990. Footprint prediction of scalar fluxes using a Markovian analysis. Boundary-Layer Meteorol. $52,247-258$. 
Lloyd, C.R., P. Bessemoulin, F.D. Cropley, A.D. Culf, A.J. Dolman, J. Elbers, B. Heusinkveld, J.B. Moncrieff, B. Monteny, A. Verhoef, 1997. A comparison of surface fluxes at the HAPEX-Sahel fallow bush sites. J. Hydrol., 188-189:400-425.

Mahrt, L., 1998. Flux sampling errors for aircraft and towers. J. Atmos. Oceanic Technol. 15, 416-429.

McCaughey, J.H., Lafleur, P.M., Joiner, D.W., Bartlett, P.A., Costello, A.M., Jelinski, D.E., Ryan, M.G., 1997. Magnitudes and seasonal patterns of energy, water, and carbon exchanges at a boreal young jack pine forest in the BOREAS northern study area. J. Geophys. Res. 102 (D24), 28997-29007.

Moncrief, J.B., Malhi, Y., Leuning, R., 1996. The propagation of errors in long-term measurements of land-atmosphere fluxes of carbon and water. Global Change Biol. 2, 231-240.

Moore, C.J., 1986. Frequency response corrections for eddy correlation systems. Boundary-Layer Meteorol. 37, 17-35.

Nie, D., Kanemasu, E.T., Fritschen, L.J., Weaver, H.L., Smith, E.A., Verma, S.B., Field, R.T., Kustas, W.P., Stewart, J.B., 1992. An intercomparison of surface energy flux measurement systems used during FIFE 1987. J. Geophys. Res. 97 (D17), 18715-18724.

Norman, J.M., J.M. Welles, D.K. McDermitt, 1992. Estimating canopy light-use and transpiration efficiencies from leaf measurements. LICOR Application Note 105, LICOR, Lincoln, NE 68504.

Reda, I., 1996. Results of NREL pyrheliometer comparisons, 1-5 October 1996. NPC1096, National Renewable Energy Laboratory, Measurement and Instrumentation Team.

Sauer, T.J., Norman, J.M., Tanner, C.B., Wilson, T.B., 1995. Measurements of heat and vapor transfer coefficients at the soil surface beneath a maize canopy using source plates. Agric. For. Meteorol. 75, 161-189.

Sellers, P.J., Hall, F.G., Asrar, G., Strebel, D.E., Murphy, R.E., 1992. An overview of the first international satellite land surface climatology project (ISLSCP) field experiment (FIFE). J. Geophys. Res. 97 (D17), 18345-18371.

Sellers, P.J., Hall, F.G., Kelly, R.D., Black, A., Baldocchi, D., Berry, J., Ryan, M., Ranson, K.J., Crill, P.M., Lettenmaier, D.P., Margolis, H., Cihlar, J., Newcomer, J., Fitzjarrald, D., Jarvis, P.G., Gower, S.T., Halliwell, D., Williams, D., Goodison, B., Wickland, D., Guertin, F.E., 1997. BOREAS in 1997: experiment overview, scientific results, and future directions. J. Geophys. Res. 102 (D24), 28731-28769.

Stannard, D.I., Blanford, J.H., Kustas, W.P., Nichols, W.D., Amer, S.A., Schmugge, T.J., Weltz, M.A., 1994. Interpretation of surface flux measurements in heterogeneous terrain during the Monsoon'90 experiment. Wat. Resour. Res. 30 (5), 1227-1239.

Unland, H.E., Houser, P.R., Shuttleworth, W.J., Yang, Z.-L., 1996. Surface flux measurement and modeling at a semi-arid Sonoran Desert site. Agric. For. Meteorol. 82, 119-153.

VanLoon, W.K.P., Bastings, H.M.H., Moors, E.J., 1998. Calibration of soil heat flux sensors. Agric. For. Meteorol. 92, 1-8.

Villalobos, F.J., 1997. Correction of eddy covariance water vapor flux using additional measurements of temperature. Agric. For. Meteorol. 88, 77-83.

Wright, I.R., Gash, J.H.C., daRocha, H.R., Shuttleworth, W.J., Nobre, C.A., Maitelli, G.T., Zamparoni, C.A.G.P., Carvalho, P.R.A., 1992. Dry season micrometeorology of central Amazonian ranchland. Q.J.R. Meteorol. Soc. 118, 1083-1099. 